\title{
THE TESTING OF GLASS VOLUMETRIC APPARATUS.
}

\author{
By N. S. Osborne and B. H. Veazey.
}

\section{CONTENTS}

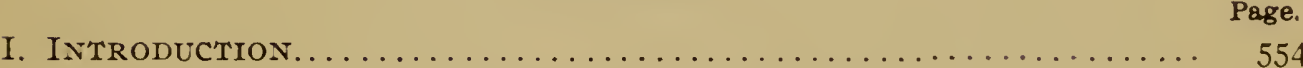

II. SPECIFICATIONS FOR Glass Volumetric Apparatus:

I. Types of apparatus admitted for test.............. 556

2. General specifications-

(a) Units of capacity employed ................ 556

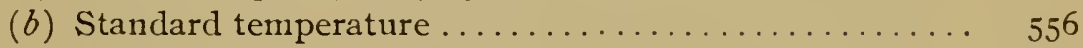

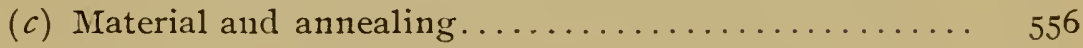

(d) Design and workmanship................... 556

(e) Inscriptions......................... 557

3. Special requirements-

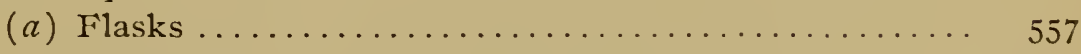

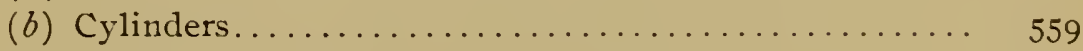

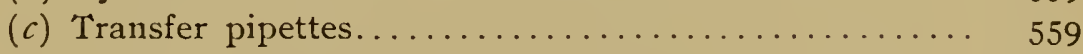

(d) Burettes and measuring pipettes............. 550

(e) Burette and pipette tips.................. 560

4. Special rules for manipulation-

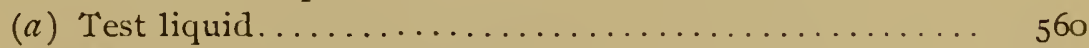

(b) Method of testing........................ $56 \mathrm{r}$

(c) Cleanliness of apparatus..................... $56 \mathrm{I}$

(d) Flasks and cylinders ......................... 56 I

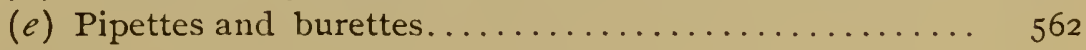

5. Tolerances-

(a) Flasks.............................. $5_{562}$

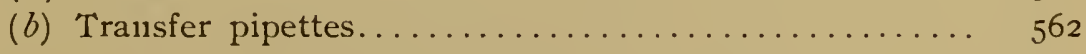

(c) Burettes and measuring pipettes............. $56_{3}$

(d) Cylinders ................................. 563

(e) Delivery time ............................ $56_{3}$

III. TESTS MADE BY THE BUREAU OF STANDARDS:

I. Nature of tests............................. ${ }_{564}$

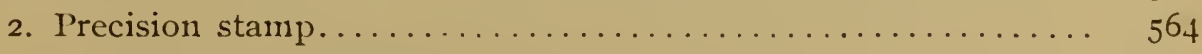

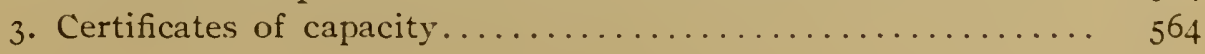

4. Special tests .............................. 564 


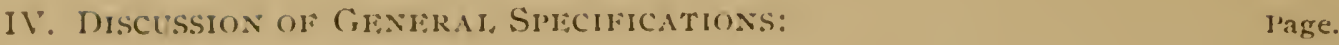

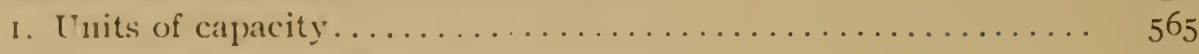

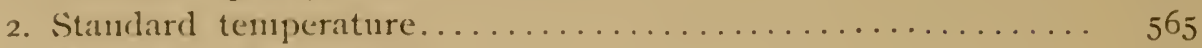

3. Material and annealing ......................... 566

4. Inscriptions.............................. 566

V. MANIPUATION:

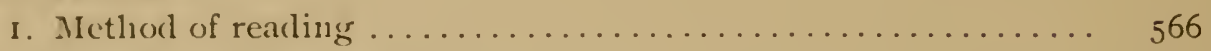

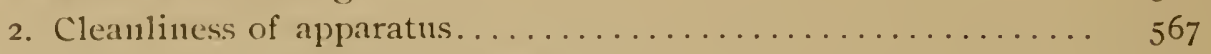

3. Use of liquids other than water ................ 574

4. Effect of temperature on residue in burettes and pipettes..... $57 \mathrm{~S}$

5. Aroidance of unnecessary heating of apparatus.......... 579

VI. FIASKS AND CYIINDERS:

I. Difference in volume delivered and contained............ 579

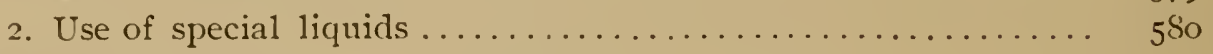

VII. TRANSFER PIPETTES:

I. Design $\ldots \ldots \ldots \ldots \ldots \ldots \ldots \ldots \ldots \ldots \ldots \ldots \ldots \ldots \ldots \ldots \ldots \ldots \ldots \ldots \ldots \ldots$

VIII. BURETTES AND MEASURING PIPETTES:

I. Burette drainage and outflow time $\ldots \ldots \ldots \ldots \ldots \ldots \ldots \ldots \ldots 5^{s_{3}}$

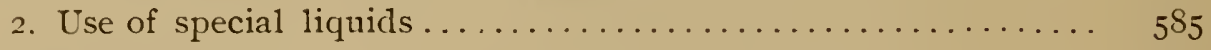

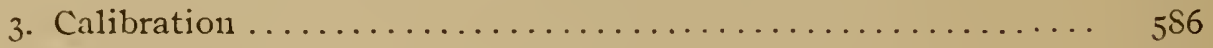

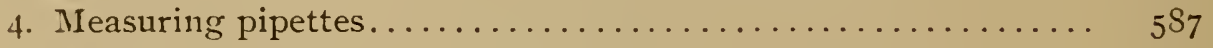

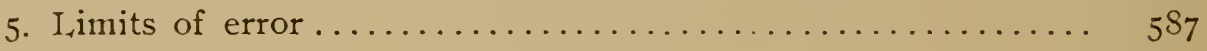

IX. METHODS OF TESTING:

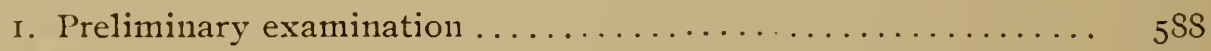

2. Methods of cleaning apparatus.................. ${ }_{5}^{88}$

3. Measurement of capacity-

(a) Testing flasks by direct measurement............ 588

(b) Testing flasks, pipettes, and burettes by weighing.... 590

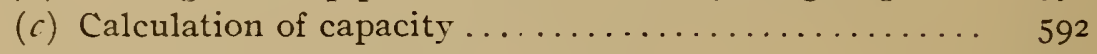

(d) Tables used in calculating capacity............ 594

\section{INTRODUCTION.}

The Bureau of Standards published November I, I904, Bureau Circular No. 9, on "Testing of glass volumetric apparatus," containing specifications for glass volumetric apparatus, the verification of which would be undertaken, and also regulations for testing such apparatus.

As stated in the circular, the specifications with few exceptions were made to agree with those reconninended by a committee of the American Chemical Society, consisting of Prof. E. W. Morley, cliairman; Prof. Artlur A. Noyes; Prof. Theodore W. Richards, and Mr. E. E. Ewell. 
In preparing the specifications, the regulations of the Kaiserliche Normal-Eichungs-Komn1ission of Germany were freely drawn upon and in many cases adopted without appreciable change. In cases, however, where the experimental work of this bureau indicated the desirability of modifications they were adopted.

Since the first publication of these regulations slight changes, suggested by the work of testing, have been introduced by revision of Circular No. 9, as "second edition," January I6, I905, and "third edition," February I, 1906.

From the fact that some difficulty lias been experienced by manufacturers in complying with the specifications, and that users of apparatus have written in certain cases for explanations of the regulations, and also since several additional changes are deemed advisable, the occasion of the third revision of the regulations is taken to discuss in more detail the various specifications and rules for manipulation, to publish the results of experimental work having a direct bearing on construction and use, and to describe the methods employed at this bureau in testing volumetric apparatus.

A number of tables compiled for use in this work have been added for the convenience of those wishing to do their own testing.

The regulations included in this article, consisting of general specifications, special requirements, rules for manipulation, limits of error, and tests performed by this bureau, are as last revised and in the form shortly to be issued in Bureau Circular No. 9, fourth edition.

\section{SPECIFICATIONS FOR GLASS VOLUMETRIC APPARATUS ACCEPTED FOR TEST.}

The primary purpose of these specifications is to define the requisite qualifications for precision apparatus.

The bureau aims to encourage excellence in quality by cooperating with makers and users of apparatus, and to this end endeavors to assist manufacturers in establishing standards and perfecting methods. In order that users of standardized apparatus may fully benefit by the facilities of the bureau it is necessary for them when purchasing apparatus to be submitted for test to require that the apparatus shall comply with the specifications. By adnitting for test only apparatus conforming to these standards the work of test- 
ing is confined to apparatus whose utility is sufficient to justify the labor expended in the accurate calibration. Certain of the specifications, such as those regarding quality of glass and process of annealing before calibration, are for their fulfillment dependent largely on the integrity of the maker. Only by supporting conscientious makers in giving consideration, first, to quality, and, second, to cost, can users of standardized apparatus secure a high degree of excellence.

1. Types of Apparatus which will be Regularly Admitted for Test.-Measuring flasks; measuring cylinders, with or without subdivisions; transfer pipettes, i. e., withont subdivisions; burettes and measuring pipettes, with partial or complete subdivisions.

2. General Specifications-

(a) Units of capacity.-The liter, defined as the volume occupied by a quantity of pure water at $4^{\circ} \mathrm{C}$. having a mass of I kilogram, and the one-thousandth part of the liter, called the milliliter or cubic centimeter, ${ }^{1}$ are employed as units of capacity.

(b) Standard temperature.--Twenty degrees Centigrade is regarded by the bureau as the standard temperature for glass volumetric apparatus, and an extra charge will be made for testing apparatus graduated for use at other temperatures.

(c) Material and annealing.-The material should be of best quality of glass, transparent and free from striæ, which adequately resists chemical action, and has small thermal hysteresis. All apparatus should be thoroughly annealed at $400^{\circ} \mathrm{C}$. for 24 hours and allowed to cool slowly before being graduated.

(d) Design and workmanship.-The cross section must be circular and the shape must permit of complete emptying and drainage.

Instruments having a base or foot must stand solidly on a level surface, and the base must be of such size that the instruments will stand on a plane inclined at $5^{\circ}$. Stoppers and stopcocks must be so ground as to work easily and prevent leakage.

The parts on which graduations are placed must be cylindrical for at least I cm on each side of every mark, but elsewhere may be enlarged to secure the desired capacities in convenient lengths.

\footnotetext{
${ }^{1}$ The cubic centimeter is not exactly the one-thousandth part of the liter, but the difference is of no consequence in volumetric analssis.
} 
The graduations should be of uniform width, continuous and finely but distinctly etched, and must be perpendicular to the axis of the apparatus. All graduations must extend at least halfway around, and on subdivided apparatus every tenth mark, and on undivided apparatus all marks must extend completely around the circumference.

The space between two adjacent marks must not be less than $I$ millimeter. The spacing of marks on completely subdivided apparatus must show no evident irregularities, and sufficient divisions nust be numbered to readily indicate the intended capacity of any interval. Apparatus which is manifestly fragile or otherwise defective in construction will not be accepted.

(e) Inscriptions.-Every instrument must bear in permanent legible characters the capacity in liters or cubic centimeters, the temperature in Centigrade degrees at which it is to be used, the method of use, i. e., whether to contain or to deliver, and on instruments which deliver through an outflow nozzle the time required to empty the total nominal capacity with unrestricted outflow must be likewise indicated.

Every instrument should bear the name or trade-mark of the maker. Every instrument must bear a permanent identification number, and detachable parts, such as stoppers, stopcocks, etc., belonging thereto must bear the same number.

Figs. I, 2, and 3 (two-fifths natural size) illustrate several arrangements of designating marks which are considered suitable.

3. Special Requirements.-(a) Flasks.-At the capacity mark or marks on a flask the inside diameter should be within the following limits:

\begin{tabular}{r|r|r|r|r|r|r|r|r}
\hline $\begin{array}{r}\text { Capacity of flask (in cc) up to and } \\
\text { including ..................... }\end{array}$ & 2,000 & 1,000 & 500 & 250 & 200 & 100 & 50 & 25 \\
Maximum diameter (in mm) ........ & 25 & 20 & 18 & 15 & 13 & 12 & 10 & 8 \\
Minimum diameter (in mm) ........ & 18 & 14 & 12 & 10 & 9 & 8 & 6 & 6 \\
\hline
\end{tabular}

The neck of a flask must not be contracted above the graduation mark. 
Bulletin of the Bureau of Standards. [Vol.4, No.4.

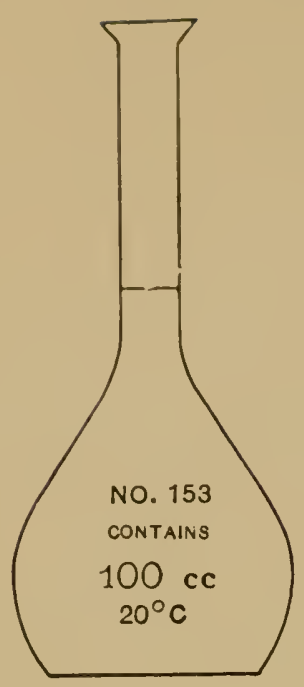

Fig. 1.

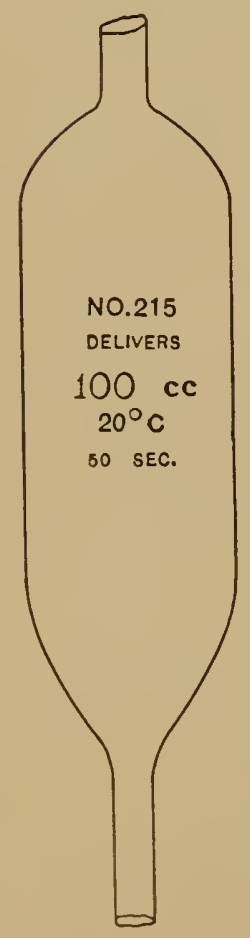

Fig. 2.

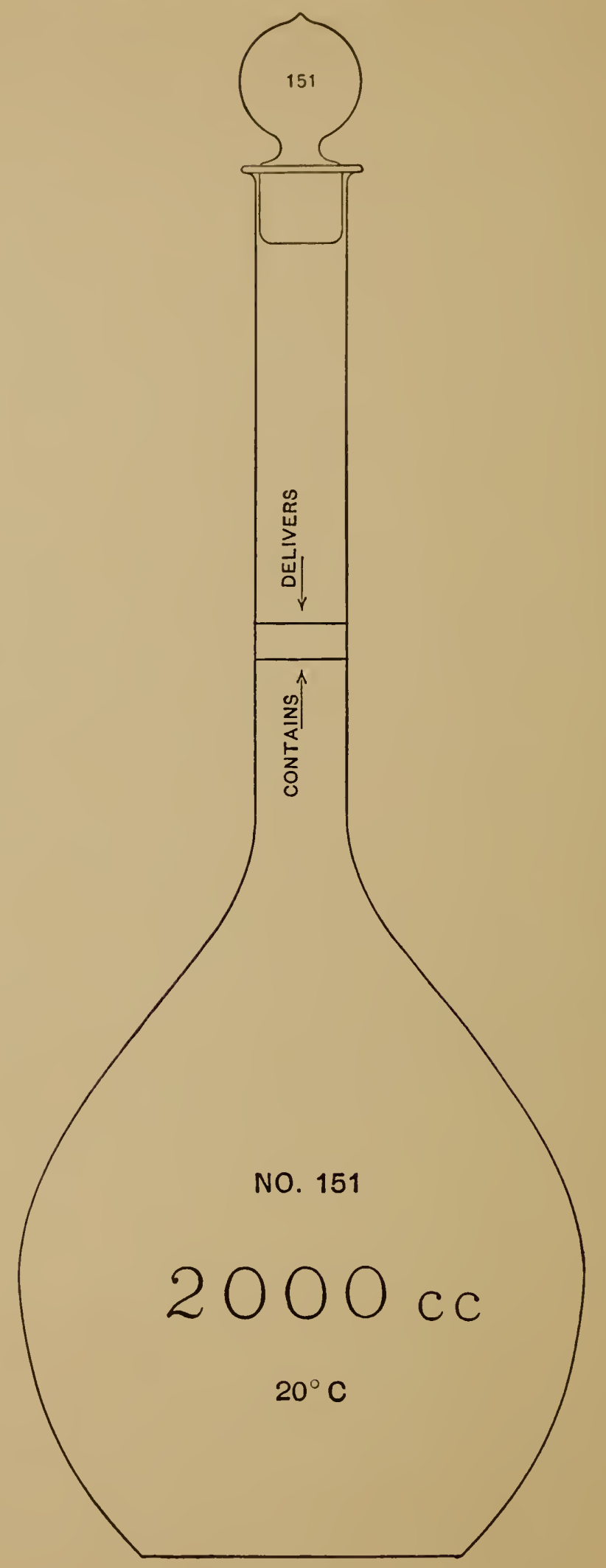

Fig. 3. 
The capacity mark on any flask must not be nearer the end of the cylindrical portion of the neck than specified below:

\begin{tabular}{|c|c|c|}
\hline Capacity & $\begin{array}{c}\text { Distance from Upper } \\
\text { End }\end{array}$ & $\begin{array}{c}\text { Distance from Lower } \\
\text { End }\end{array}$ \\
\hline $100 \mathrm{cc}$ or less. & $3 \mathrm{~cm}$ & $1 \mathrm{~cm}$ \\
\hline More than $100 \mathrm{cc}$. & $6 " 6$ & 26 \\
\hline
\end{tabular}

Flasks of I liter or more but not less may be graduated both to contain and to deliver, provided the intention of the different marks is clearly indicated.

(b) Cylinders.-Only cylinders graduated to contain will be accepted for test.

The inside diameter of cylinders must not be more than one-fifth the graduated length.

(c) Transfer pipettes.-Pipettes for delivering a single volume are designated "transfer" pipettes.

The suction tube of each transfer pipette must be at least $16 \mathrm{~cm}$ long, and the delivery tube must not be less than $3 \mathrm{~cm}$ nor more than $2.5 \mathrm{~cm}$ long.

The inside diameter of any transfer pipette at the capacity mark must not be less than $2 \mathrm{~mm}$ and must not exceed the following limits:

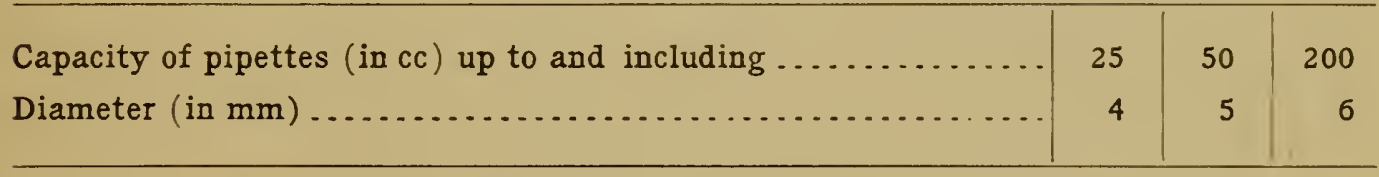

The outside diameter of the suction and delivery tubes of transfer pipettes exclusive of the tip must not be less than $5 \mathrm{~mm}$.

The capacity mark on transfer pipettes must not be more than 6 cin from the bulb.

The outlet of any transfer pipette must be of such size that the free outflow shall last not more than one minute and not less than the foilowing for the respective sizes:

\begin{tabular}{ll|r|r|r|r|r}
\hline Capacity (in cc) up to and including ............ & 5 & 10 & 50 & 100 & 200 \\
Outflow time (in seconds) $\ldots \ldots \ldots \ldots \ldots \ldots \ldots \ldots$. & 15 & 20 & 30 & 40 & 50 \\
\hline
\end{tabular}


(d) Burctles and measuring pipcttes.-Only those emptying through a nozzle permanently attached at the bottom are accepted for test.

The distance between the extreme graduations nunst not exceed $65 \mathrm{~cm}$ on burettes nor $35 \mathrm{~cm}$ on measuring pipettes.

The rate of ontflow of burettes and measuring pipettes must be restricted by the size of the tip and for any graduated interval the time of free ontflow must not be more than three minutes nor less than the following for the respective lengths:

\begin{tabular}{|c|c|c|c|c|c|c|c|}
\hline \multicolumn{2}{|c|}{ Length Graduated } & \multicolumn{2}{|c|}{ Time of Outflow } & \multicolumn{2}{|c|}{ Length Graduated } & \multicolumn{2}{|c|}{ Time of Outflow } \\
\hline \multicolumn{2}{|c|}{65 Centimeters } & \multicolumn{2}{|c|}{140 Seconds } & \multicolumn{2}{|c|}{35 Centimeters } & \multicolumn{2}{|c|}{60 Seconds } \\
\hline 60 & “ & 120 & "6 & 30 & “ & 50 & " \\
\hline 55 & “ & 105 & “ & 25 & “ & 40 & “ \\
\hline 50 & “ & 90 & " & 20 & “ & 35 & “ \\
\hline 45 & “ & 80 & " & 15 & “ & 30 & “ \\
\hline 40 & “ & & " & & & & \\
\hline
\end{tabular}

The upper end of any measuring pipette must be not less than Io cm from the uppermost mark and the lower end not less than 4 cin from the lowest mark.

(e) Burette and pipette tips.-Burette and pipette tips should be made with a gradual taper of from $2 \mathrm{~cm}$ to $3 \mathrm{~cm}$, the taper at the extreme end being slight.

A sudden contraction at the orifice is not permitted and the tip must be well finished.

In order to facilitate the removal of drops and to avoid splashing when the instrument is vertical, the tip should be bent slightly.

The approved form of tips for burettes, measuring pipettes, and transfer pipettes is shown in fig. 4 .

4. Special Rules for Manipulation.-These rules indicate the essential points in the manipulation of volumetric apparatus which n11ust be observed in order that the conditions necessary to obtain accurate measurements may be reproduced.

(a) Test liquid.-Apparatus will be tested with water and the capacity determined will, therefore, be the volume of water contained or delivered by an instrument at its standard temperature. 
(b) Method of reading.-In all apparatus where the volume is limited by a meniscus the reading or setting is made on the lowest point of the meniscus. In order that the lowest point may be observed it is necessary to place a shade of some dark material immediately below the meniscus, which renders the profile of the meniscus dark and clearly visible against a light background. A convenient device for this purpose is a collar-shaped section of thick black rubber tubing, cut open at one side and of such size as to clasp the tube firmly.

(c) Cleanliness of apparatus.-Apparatus must be sufficiently clean to permit uniform wetting of the surface.

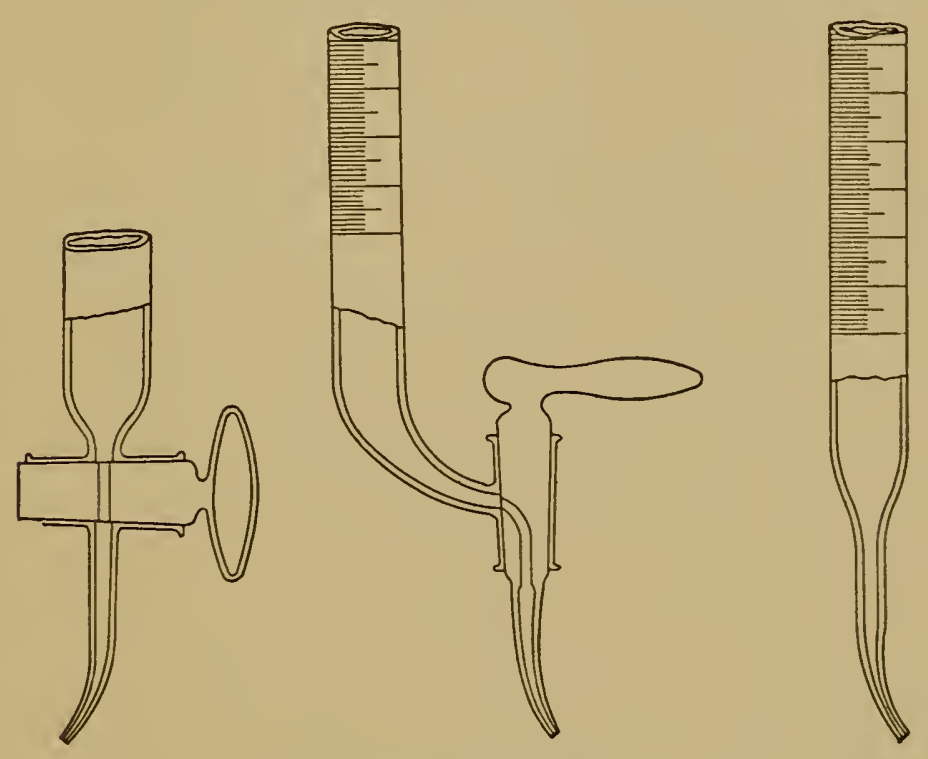

Fig. 4 (two-fifths natural size).

(d) Flasks and cylinders. - In filling flasks and cylinders the entire interior of the vessel will be wetted, but allowed a sufficient time to drain before reading. Before completely filling to the capacity mark flasks should be well shaken to completely mix the contents.

Flasks and cylinders when used to deliver should be emptied by gradually inclining them until when the continuous stream has ceased they are nearly vertical. After half a minute in this position the mouth is brought in contact with the wet surface of the receiving vessel to remove the adhering drop. 
(c) Pipelles and bureltes. - In filling pipettes and burettes excess liquid adhering to the tip should be removed when completing the filling.

In emptying pipettes and burettes they should be held in a vertical position, and after the continuous unrestricted outflow ceases the tip should be touched with the wet surface of the receiving vessel to complete the emptying.

Stopcocks, when used, should be completely open during emptying.

Burettes should be filled nearly to the top, and the setting to the zero mark made by slowly emptying.

While under normal usage the measurements ordinarily are from the zero mark, other initial points may be used on burettes of standard form without serious error.

\section{Tolerances.}

(a) Flasks.

\begin{tabular}{c|c|c}
\hline \multirow{2}{*}{$\begin{array}{c}\text { Capacity Less Than and } \\
\text { Including }\end{array}$} & \multicolumn{2}{|c}{ Limit of Error } \\
\cline { 2 - 3 } $25 \mathrm{cc}$ & If to Contain & If to Deliver \\
$50 "$ & $0.03 \mathrm{cc}$ & $0.05 \mathrm{cc}$ \\
$100 "$ & .05 " & $.10 "$ \\
$200 "$ & .08 " & $.15 "$ \\
$300 "$ & $.10 "$ & $.20 "$ \\
$500 "$ & $.12 "$ & $.25 "$ \\
$1,000 "$ & $.15 "$ & $.30 "$ \\
$2,000 "$ & $.30 "$ & $.50 "$ \\
\hline
\end{tabular}

(b) Transfer pipettes.

\begin{tabular}{c|c}
\hline Capacity Less Than and Including & Limit of Error \\
\hline $2 \mathrm{cc}$ & $0.006 \mathrm{cc}$ \\
5 " & .01 " \\
10 " & .02 " \\
$30 "$ & .03 " \\
$50 "$ & .05 " \\
$100 "$ & .08 " \\
$200 "$ & .12 " \\
\hline
\end{tabular}


(c) Burettes and measuring pipettes.

\begin{tabular}{|c|c|c|}
\hline \multirow{2}{*}{$\begin{array}{l}\text { Capacity of Total Graduated } \\
\text { Portion Less Than and In- } \\
\text { cluding }\end{array}$} & \multicolumn{2}{|c|}{ Limit of Error of Total or Partial Capacity } \\
\hline & Burettes & Measuring Pipettes \\
\hline $2 \mathrm{cc}$ & & $0.01 \mathrm{cc}$ \\
\hline 5 “ & $0.01 \mathrm{cc}$ & $.02 “$ \\
\hline $10 "$ & $.02 “$ & $.03 “$ \\
\hline 30 " & .03 “ & .05 " \\
\hline $50 " 6$ & $.05 “$ & $.08 “$ \\
\hline $100^{\prime 6}$ & $.10^{\prime \prime}$ & $.15^{\prime}$ \\
\hline
\end{tabular}

Further, the error of the indicated capacity of any ten consecutive subdivisions must not exceed one-fourth the capacity of the smallest subdivision.

(d) Cylinders.

\begin{tabular}{|c|c|c|c|}
\hline $\begin{array}{c}\text { Capacity of Total Grad- } \\
\text { uated Portion Less } \\
\text { Than and Including }\end{array}$ & $\begin{array}{l}\text { Limit of Error of Total } \\
\text { or Partial Capacity }\end{array}$ & $\begin{array}{c}\text { When the Smallest Sub- } \\
\text { divisions are Not } \\
\text { More Than }\end{array}$ & $\begin{array}{c}\text { Limit of Error of any } \\
\text { Ten Consecutive } \\
\text { Divisions }\end{array}$ \\
\hline $30 \mathrm{cc}$ & $0.06 \mathrm{cc}$ & $0.2 \mathrm{cc}$ & $0.1 \mathrm{cc}$ \\
\hline $50^{\prime 6}$ & $.10^{66}$ & 1.06 & .26 \\
\hline $100 "$ & $.30 ،$ & $2.0 " 6$ & $.4 "$ \\
\hline $200 " 6$ & $.50 \%$ & 10.0 " & 1.06 \\
\hline $500 "$ & $1.20^{\prime \prime}$ & 20.0 " & $2.0 "$ \\
\hline 1,000 & 2.00 & & \\
\hline 2,000 & $4.00 " 6$ & & \\
\hline
\end{tabular}

The delivery time marked on any instrument must be within the limits prescribed in the specifications and the error permitted in the marked delivery time is as follows:

(e) Delivery time.

\begin{tabular}{|c|c|}
\hline Delivery Time Less Than and Including & Limit of Error \\
\hline $15 \mathrm{sec}$. & $3 \mathrm{sec}$ \\
\hline $20 "$ & 4 “ \\
\hline $30 "$ & 6 “ \\
\hline 50 “ & 8 “ \\
\hline 100 “ & $15 “$ \\
\hline $200 " 6$ & $20 "$ \\
\hline
\end{tabular}




\section{TESTS MADE BY THE BUREAU OF STANDARDS.}

1. Nature of Tests.-Apparatus submitted for test is first examined as to its conformity with the specifications concerning design and marks, including test of outflow time where this is limited.

Apparatus having subdivisions is examined as to the apparent regularity of spacing.

If the apparatus complies with the specifications in other respects, a test is made of its capacity.

This test may be either to ascertain whether the capacity is correct within the prescribed limits of error or to determine the correction for use in precise measurements.

2. Precision Stamp.-If the result of examination and test of flasks, cylinders, and transfer pipettes indicates a satisfactory conformity to the specifications, the official precision stamp, consisting of the letters "U.S." and the year date, or the last two figures thereof, surrounded by a circle, is etched as shown below:

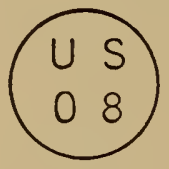

3. Certificates of Capacity.-Burettes and measuring pipettes will be tested for at least five intervals, and if found to conform to the specified requirements will be assigned a test number as shown below:

$$
\begin{aligned}
& \text { B. S. No. } 1763 \\
& \text { I } 908
\end{aligned}
$$

A certificate will be furnished, giving the volumes delivered by the intervals tested.

When desired, certificates of capacities of flasks, cylinders, and transfer pipettes will also be furnished.

4. Special Tests.-Apparatus of approved design intended for special purposes, not conforming with the specifications, will be received for test only by previous arrangement, when accompanied by complete description of the intended use.

The bureau reserves the right to reject any apparatus on points affecting its accuracy or utility not covered by the regulations. 


\section{DISCUSSION OF GENERAL SPECIFICATIONS.}

1. Units of Capacity.-The liter is defined in these specifications as the volume occupied by a quantity of pure water at $4^{\circ} \mathrm{C}$. having a mass of one kilogram. The one-thousandth part of the liter, the milliliter, called the cubic centimeter for convenience, is also employed as a unit of capacity. The milliliter is about I.000029 true cubic centimeters, according to the recent determinations of the International Bureau of Weights and Measures, ${ }^{2}$ but this difference is of no consequence in volumetric analysis.

The Mohr ${ }^{3}$ system of capacity units is not employed by this bureau, since it is difficult of complete definition, is not superior to the metric system in point of convenience, and introduces much confusion. The Kaiserliche Normal-Eichungs-Kommission no longer employs the Mohr unit for reasons given by W. Schloesser, ${ }^{45}$ who concludes that there is not sufficient justification for its use. On the other hand, the National Physical Laboratory of England recognizes the Mohr unit, and requires that vessels graduated in Mohr units be marked "gramme" or "grm.," together with the temperature at which the vessel has the specified number of such units of capacity.

2. Standard Temperature. - Since the capacity of glass-measuring apparatus varies with the temperature, it is necessary to specify the temperature when giving the capacity.

Another equally important reason for specifying the temperature is that in many liquids, measured volumetrically, the very properties whose relation is determined by these measurements change with the temperature, often to an extent more significant than the change in capacity. The temperature specified for use of apparatus is designated as the standard temperature.

\footnotetext{
${ }^{2}$ Procès-Verbaux, Comité Int. P. et Mies. (2), IV, p. 52.

${ }^{3}$ The Mohr unit may be defined as the volume occupied at an arbitrary standard temperature by that mass of water which, when weighed with brass weights in air having a barometric pressure of $760 \mathrm{~mm}$, the arbitrary standard temperature, and a mean content of moisture and $\mathrm{CO}_{2}$ has an apparent weight of one gram.

4 Über die Einrichtung und Prüfung der Messgeräte für Massanalyse.

${ }^{5}$ Zs. für Angewandte Chemie, I903, pp. 955 to 960. Zs. für Analytische Chemie, I907, pp. 393 to 400.
} 
For many purposes the actual temperature chosen as standard is of minor importance provided all instruments used in conjunction have the same standard temperature, but where absolute measurements are desired, it is advantageous to employ a standard temperature which approximates the average temperature of the laboratory, or at least is readily attainable. The temperature $20^{\circ} \mathrm{C}$. closely fulfills these conditions in this country and has consequently been chosen as the standard temperature for glass volumetric apparatus.

3. Material and Annealing.-Apparatus upon which especial care is bestowed to attain precision is of superior value only if it possesses permanence.

It is a well known fact that glass changes mechanically with time after manufacture into apparatus, the amount of such change depending upon the kind of glass and upon its heat treatment. If after manufacture the glass is annealed, the subsequent change in volume is usually of little importance for ordinary volumetric apparatus. Although annealing is of minor importance volumetrically for the better thermometer glasses, it should always be carried out to relieve mechanical stresses since these endanger the integrity of the apparatus.

4. Inscriptions.-These are necessary in order that the user may readily ascertain essential information, such as the capacity, standard teinperature, and manner of use. Identification numbers are necessary both for the user and for the testing bureau in order to avoid confusion in identity or assembling.

Indication of the outflow time permits the user to ascertain whether the tips of burettes and pipettes have undergone alteration.

\section{SPECIAL RULES FOR MANIPULATION.}

The aim has been to make these rules comply as fully as possible with the most approved methods of practice. To a great extent the reasons for the indvidual rules are self-evident. In certain cases, however, the significance and justification of the rules have been discussed under separate headings.

1. Method of Reading.-The specifications require that all graduations extend at least halfway around. This requirement makes it possible to avoid parallax by so placing the eye that when observ- 
ing the meniscus the front and back portions of the graduation coincide. The true outline of the meniscus is recognized with difficulty unless the meniscus is so shaded as to bring the meniscus and the background into contrast. This is effected by clasping around the graduated tube a collar-shaped piece of thick black rubber tubing. When this collar is placed immediately below the meniscus and a white background employed, the profile of the meniscus is very definitely outlined and is practically coincident in position with the liquid surface, while if this precaution is neglected the apparent ontline of the meniscus may be considerably in error.

The exclusion of burettes with short graduations has been to some extent criticised, but experience has shown that these burettes are not capable of the accuracy required in precise work, on account of the error in reading due to parallax.

2. Cleanliness of Apparatus.-Certain contaminations, especially grease, adhering to the walls of measuring vessels prevent them from being uniformly wetted. The tendency of water to collect into drops instead of adhering to the glass surface as a continuous film indicates imperfect wetting due to uncleanliness.

Imperfect wetting causes irregularities in capacity by distorting the meniscus. In instruments to deliver it also causes irregularities by affecting the residue adhering to the walls.

Since accuracy in the volume contained or delivered is possible only when the liquid will form a continuous film on the walls of the measuring ressel, this condition is prescribed as a test of cleanliness.

But even when the surface of the apparatus fulfills this condition, variations in the apparent capacity may still occur, cansed by contamination of the liquid surface by minute quantities of fatty or other organic substances. This effect is due to the formation of a film on the surface which produces a change in the surface tension and a consequent variation in the shape of the meniscus.

The phenomena of surface contanination of liquids have been studied experimentally by Rayleigh ${ }^{6}$, Nansen ${ }^{7}$, Pockels ${ }^{8}$, and others, but since the effect upon volumetric measurements has not to our

\footnotetext{
${ }^{6}$ Rayleigh, Phil. Mag., 4S, pp. 321-337; is99.

${ }^{7} \mathrm{~F}$. Nansen, Norwegian North Polar Expedition, I893-I896, Scientific Results, 10 , p. $6 \mathrm{I} ; 1900$.

${ }^{8}$ Agnes Pockels, Annalen der Physik, $3{ }^{1} 3$ (IV)S, p. S54; 1902.
} 
knowledge been considered, it has been made the subject of an investigation to ascertain its importance.

The questions which it was desired to answer were: $(a)$ To what extent is the surface tension of the meniscus in volumetric apparatus changed by contamination when various methods of cleaning and drying are employed? (b) If the surface tension of the meniscus is thus changed, to what extent is the apparent capacity affected? (c) How may appreciable errors from this cause be avoided ?

In the experimental portion of the investigation a one-liter flask was used. The normal capacity, deviations from which were measured was the capacity when the surface of the meniscus was uncontaminated. Previous observers have shown that surface contaminations are removed by overflowing. The flask was therefore so modified that this operation could be performed.

The flask is shown in Fig. 5. Tube (a), attached to the flask by a ground joint, carries the overflow nozzle. Tube $(b)$ carries a stopcock, so that the meniscus can be lowered to the mark after overflow. The inside diameter at the graduation mark was $16.3 \mathrm{~mm}$. The distance from the graduation to the ground joint was $65 \mathrm{~mm}$.

The volume of water contained by the flask under varions conditions was determined by weighing; the temperature was observed on an enclosed scale thermometer, inserted after setting the meniscus to the mark. To prevent evaporation the flask was closed during weighing by means of a rubber stopper which served to hold the thermometer. To permit comparisons the apparent capacity of the flask resulting from these determinations was reduced to $20^{\circ} \mathrm{C}$, the observed temperatures being between $18^{\circ}$ and $22^{\circ} \mathrm{C}$.

The following methods of preparing and manipulating the flask were employed:

The entire interior of the flask, the overflow tube, the stopcock and thermometer were thoroughly cleaned with funing sulphuric acid before each series of observations. The parts were thoroughly rinsed with tap water and then with distilled water. After the interior of the flask had been finally rinsed either with water, with alcohol redistilled from caustic soda, or with commercial 95 per cent alcohol, the parts were dried by evaporation. (In Series I and VIII the flask was not dried.) The air used in drying the flask was purified and dried by passing it first through sulphuric acid and then 
througl two tubes, the first containing glass wool and the second clean cotton. After cleaning and drying, the stopcock was slightly greased.

The filling of the flask was made in four ways, designated as A, $\mathrm{B}, \mathrm{C}$, and $\mathrm{D}$.

Method A: The flask was filled from a nozzle placed about I 5 mm. above the mark, the outflow tube filled to the tip, and the meniscus raised to the mark.

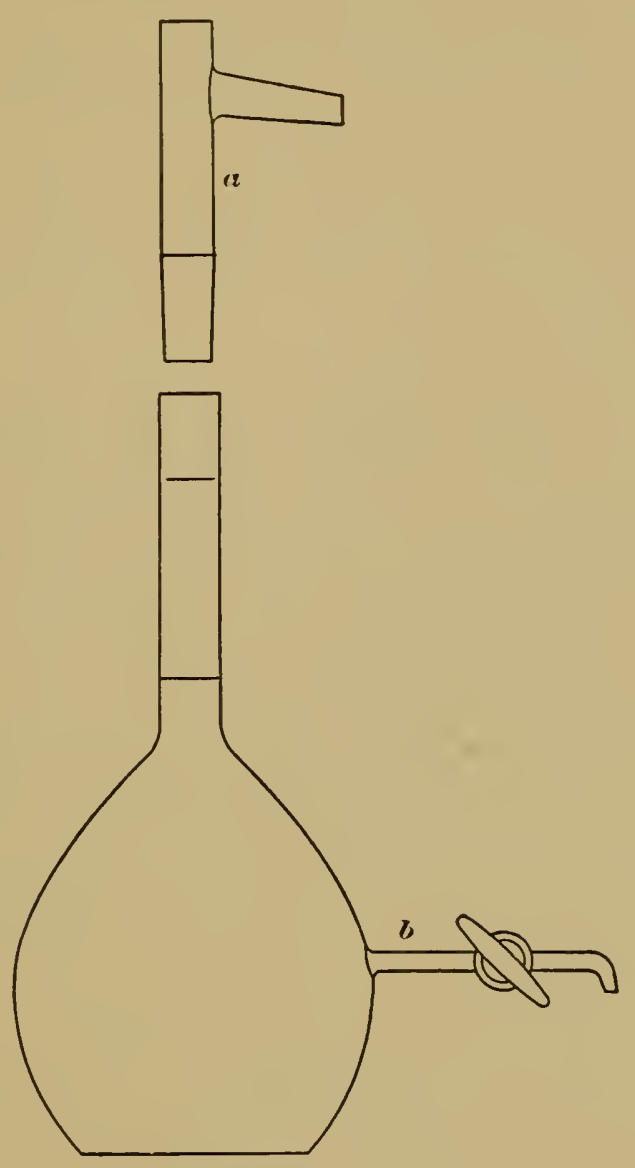

Fig. 5.

Method B: Following the weighing for $\mathrm{A}$ the thermometer was removed carefully and dried, the neck was filled to the ground-glass joint without disturbing the meniscus surface unnecessarily, and the setting made by means of the stopcock and outflow tube.

Method C: After B the overflow tube was inserted and water admitted until about $500 \mathrm{cc}$. had overflowed through the spout. The water was lowered below the ground joint, the overflow tube removed, and the meniscus slowly lowered to the mark as in B. 
Method D: After C the neck was dried by evaporation without disturbing the meniscus, using clean dry air, after which the setting was made as in $\mathrm{A}$.

The results have been referred to the mean normal capacity of the flask; that is, the capacity after overflowing. The amount of water on the neck was determined and eliminated from the results. Consequently, Tables I and II give the normal capacity minus actual capacity. This quantity we will term the defect in capacity.

The experimental work was performed by Miss G. C. McDermut, to whom credit it due for great care in manipulation.

\section{TABLE I.}

Observed Defect in Capacity.

\begin{tabular}{|c|c|c|c|c|c|}
\hline Series & A & B & C & $\mathrm{D}$ & Remarks \\
\hline I & $+0.020 \mathrm{cc}$ & & $\begin{array}{l}-0.003 c c \\
-0.004 \cdots\end{array}$ & $\begin{array}{l}-0.006 c c \\
-0.007 ،\end{array}$ & Flask not dried except neck. \\
\hline II & $+0.044 \mathrm{cc}$ & 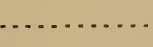 & & $-0.011 \mathrm{cc}$ & Rinsed with water, dried. \\
\hline III & $\begin{array}{l}+0.061 \mathrm{cc} \\
+0.057 ، \\
+0.060 \cdots\end{array}$ & $\begin{array}{l}+0.006 c c \\
+0.007 ، \\
+0.007 ،\end{array}$ & $\begin{array}{r}-0.004 c c \\
0.000 \\
-0.005 \% \\
+0.009\end{array}$ & $\begin{array}{l}+0.001 \mathrm{cc} \\
-0.003 \text { “ } \\
+0.002 ،\end{array}$ & Rinsed with redistilled alcohol, dried. \\
\hline IV & $\begin{array}{l}+0.094 \mathrm{cc} \\
+0.071 ، \\
+0.085 ، \\
+0.072 ،\end{array}$ & $\begin{array}{l}+0.015 c c \\
+0.020 \cdots\end{array}$ & $\begin{array}{l}-0.006 c c \\
+0.002 ، \\
+0.006 ،\end{array}$ & $\begin{array}{l}+0.013 \mathrm{cc} \\
+0.006 \cdots\end{array}$ & Rinsed with ordinary alcohol, dried. \\
\hline v & $\begin{array}{l}+0.033 c c \\
+0.029 ، \\
+0.036 ،\end{array}$ & & & & As in (IV) except neck wet. \\
\hline VI & $\begin{array}{l}+0.001 c c \\
-0.005 ، \\
-0.002 ، \\
-0.005 ،\end{array}$ & & & & $\begin{array}{l}\text { As in (V) except agitated before } \\
\text { completely filling. }\end{array}$ \\
\hline vII & $\begin{array}{l}+0.064 c c \\
+0.054 “\end{array}$ & & & & As in (VI) except neck dry. \\
\hline VIII & $\begin{array}{l}+0.074 \mathrm{cc} \\
+0.073 ، \\
+0.055 ،\end{array}$ & $\begin{array}{l}+0.007 \mathrm{cc} \\
+0.004 “ \\
-0.001 ،\end{array}$ & $\begin{array}{l}-0.005 \mathrm{cc} \\
-0.006 ، \\
-0.007 ،\end{array}$ & $\begin{array}{l}+0.005 \mathrm{cc} \\
+0.013 ، \\
+0.009 ،\end{array}$ & $\begin{array}{l}\text { As in (I) except contaminated with } \\
\text { soap. }\end{array}$ \\
\hline
\end{tabular}

In all determinations except Series VIII the greatest care was exercised to avoid contanination other than that derived from the air or from the liquid last used for rinsing the flask. But since, in filling, 
TABLE II.

Assembled Mean Results.

\begin{tabular}{|c|c|c|c|c|c|}
\hline \multicolumn{6}{|c|}{ Defect in Meniscus Volume. } \\
\hline Series & A & B & c & $\mathrm{D}$ & Remarks \\
\hline I & $+0.020 \mathrm{cc}$ & & $-0.004 c c$ & $-0.006 c c$ & \\
\hline II & $+0.044 " ،$ & & & $+0.011 " ،$ & \\
\hline III & +0.059 “ & $+0.007 \mathrm{cc}$ & $0.000 \mathrm{cc}$ & $0.000 " ،$ & \\
\hline IV & $+0.080 \cdots$ & $+0.018 \cdots$ & +0.001 " & $+0.010 \%$ & \\
\hline v & +0.033 " & & & & \\
\hline vI & $-0.003 ،$ & & & & \\
\hline VII & +0.059 " & & & & \\
\hline vIII & $+0.067 ،$ & $+0.003 \mathrm{cc}$ & $-0.006 \mathrm{cc}$ & $+0.009 c c$ & \\
\hline
\end{tabular}

contaminations from the interior of the flask are collected on the relatively small surface of the meniscus, very small amounts cause sensible effects. Even when water twice distilled-the second time from alkaline potassium permanganate-was ised in the final rinsing, as in Series II, a sensible diminution in the capacity indicated contamination. A greater degree of contamination was produced when purified alcolol was used for drying, and a still greater contamination resulted from the use of ordinary alcoliol.

Intentional contamination was accomplished in VIII by slightly soaping a clean glass rod and touching the surface of the water. In the experiments of Miss Pockels, previonsly mentioned, the greatest contaminating effect observed was produced by soap, which reduced the surface tension of water to 0.49 of its normal value.

Comparison of Series II and III with Series VIII shows that despite the care taken in the former three series the surface tension was very low. It is evident that reasonable care in cleaning and drying does not insure a normal meniscus.

The effect of distributing the contamination over a larger surface is shown in Method B by the diminution of the defect in volume produced when after Method A the meniscus is raised to the joint and then lowered. Part of this effect is due to extension of the surface on withdrawal of the thermometer from the liquid. The volume is in most cases increased by Method $B$ nearly to normal value. In Series $\mathrm{V}$ the neck was wet to the joint when commencing the filling 
and allowed to drain until the setting was made. 'The defect was evidently less than with dry neck, but was not reduced so $1111 \mathrm{ch}$ as by Method B, sugresting that the contanination does not spread over a thin film as completely as over a free surface.

In Series VI, after wetting the entire interior of the flask from the joint down, the flask was filled abont two-thirds full, closed by a stopper, and then vigorously shaken to break up the surface and distribute its parts throughout the mass of the water. It is seen that this manipulation is apparently as effective as overflowing in destroying the effect of contamination. In Series VII the water was shaken before completing the filling, keeping the neck of the flask dry. The effect is much less than in VI, probably due in part to the less vigorous agitation of the water and partly to the smaller area over which the contanination was distributed.

The greatest defect in volume (0.080 cc) was observed in Series IV, where ordinary alcohol was used in drying the flask. To estimate the reduction in the surface tension of water corresponding to this result the defect in volume of a water meniscus $16.3 \mathrm{~mm}$ in diameter was calculated, taking for the normal surface tension of water at $20^{\circ} \mathrm{C} 72.5 \mathrm{dyn} / \mathrm{cm}$, and for contaminated water 39.3 dyn/cm. (This value corresponds to 0.54 of the normal tension, the value observed by Miss Pockels for water contaninated with tannin.) The tables computed by Bashforth and Adams ${ }^{9}$ were used. [Extrapolation was necessary, since the diameter $\mathrm{r} 6.3 \mathrm{~mm}$ lay outside the range of the table.] A defect in volume of $0.074 \mathrm{cc}$ was found, corresponding very closely with that observed in Series IV. This suggests the presence of tannin, extracted by the alcohol from the barrel in which it was kept. The surface tension, therefore, of the meniscus in this series was about 0.5 that of pure water.

The defect in capacity of apparatus caused by the contanination, which reduces the surface tension of water to 0.54 of the normal value, is shown in Table III for tubes of different dianeters. The portion of the table below the broken line is extrapolated graphicaily. Since a maximum and minimum limit can be assigned to the slope of the graph, the extrapolation is known to be correct to at least ro per cent. 
TABLE III.

\begin{tabular}{c|c|c|c}
\hline $\begin{array}{c}\text { Diameter } \\
\mathrm{mm}\end{array}$ & $\begin{array}{c}\text { Defect in Capacity } \\
\text { cc }\end{array}$ & $\begin{array}{c}\text { Diameter } \\
\mathrm{mm}\end{array}$ & $\begin{array}{c}\text { Defect in Capacity } \\
\text { cc }\end{array}$ \\
5 & 0.001 & 15 & 0.058 \\
6 & 0.003 & 16 & 0.067 \\
7 & 0.005 & 17 & 0.076 \\
8 & 0.008 & 18 & 0.085 \\
9 & 0.012 & 19 & 0.095 \\
10 & 0.018 & 20 & 0.105 \\
11 & 0.024 & 21 & 0.115 \\
12 & 0.032 & 22 & 0.125 \\
13 & 0.041 & 23 & 0.135 \\
$\ldots \ldots \ldots$ & $\ldots \ldots \ldots$ & 24 & 0.145 \\
14 & 0.049 & 25 & 0.155 \\
\hline
\end{tabular}

In Table IV is given for flasks of various capacities the limit of error, the maximum and minimum diameters of neck allowed, and the possible error from contamination for maximum and minimum diameters taken from Table III.

TABLE IV.

\begin{tabular}{|c|c|c|c|c|c|}
\hline \multirow{2}{*}{ Capacity } & \multirow{2}{*}{$\begin{array}{l}\text { Limit of } \\
\text { Error }\end{array}$} & \multicolumn{2}{|c|}{ Allowed Diameters } & \multicolumn{2}{|c|}{$\begin{array}{l}\text { Possible Error from } \\
\text { Contamination }\end{array}$} \\
\hline & & Max. & Min. & Max. Dia. & Min. Dia. \\
\hline $50 \mathrm{cc}$ & $0.05 \mathrm{cc}$ & $10 \mathrm{~mm}$ & $6 \mathrm{~mm}$ & $0.018 \mathrm{cc}$ & $0.003 \mathrm{cc}$ \\
\hline 100 "6 & 0.08 " & 12 " & 86 & 0.032 " & 0.008 \\
\hline $200 "$ & $0.10 "$ & 13 " & 9 " & 0.041 "6 & 0.012 " \\
\hline $300 " 6$ & $0.12 ،$ & 156 & $10 " 6$ & 0.058 " & 0.018 \\
\hline 500 66 & 0.15 " & 18 " & 12 " & 0.085 " & 0.032 " \\
\hline 1000 " & 0.306 & $20 " 6$ & $14 " 6$ & 0.105 ، & 0.049 " \\
\hline 2000 & $0.50 " 6$ & $25 "$ & $18 " 6$ & 0.155 ، & 0.085 \\
\hline
\end{tabular}

Table $\mathrm{V}$ gives the possible error from contamination expressed as per cent of total capacity and also as per cent of total error allowed in the specifications. 
TABLE V.

\begin{tabular}{|c|c|c|c|c|}
\hline \multirow{2}{*}{ Capaci:y } & \multicolumn{2}{|c|}{$\begin{array}{l}\text { Possible Error Per cent of } \\
\text { Total Capacity }\end{array}$} & \multicolumn{2}{|c|}{$\begin{array}{l}\text { Possible Error Per cent of } \\
\text { Allowed Error }\end{array}$} \\
\hline & Max. Dia. & Min. Dia. & Max. Dia. & Min. Dia. \\
\hline $50 \mathrm{cc}$ & 0.036 & 0.006 & 36 & 6 \\
\hline $100 "$ & 0.032 & 0.008 & 40 & 10 \\
\hline $200 “$ & 0.020 & 0.006 & 41 & 12 \\
\hline $300 " 6$ & 0.019 & 0.006 & 48 & 15 \\
\hline $500 " ،$ & 0.017 & 0.006 & 57 & 21 \\
\hline $1000 "$ & 0.011 & 0.005 & 35 & 16 \\
\hline $2000 "$ & 0.008 & 0.004 & 31 & 17 \\
\hline
\end{tabular}

The following conclusions are drawn in answer to the questions stated at the ontset: (a) The surface tension of the meniscus in volumetric apparatus is subject to a defect of about 0.5 the normal value due to contaminations not removed by the accepted methods of cleaning. (b) The capacity of ordinary measuring flasks may be affected by this change in surface tension by from one to four parts in 10,000. (c) Errors from this cause in capacity of flasks may be avoided by employing the method prescribed in the rules for manipulation of flasks, that is, thoroughly shaking the contents just before completing the filling.

3. Use of Liquids other than Water.-In order for the standardizing bureau to furnish corrections or affix the precision stamp to burettes, pipettes, and other vessels which are intended to measure liquids other than water, the particular liquid which the instrument is to measure must be employed in the test of the instrument until the behavior of that liquid has been studied in various apparatus. Until a demand has arisen for precise ressels delivering some particular liquid, it seems better for this burean to test the quality of the instrument with water only, and to ascertain that the instrument complies with the specifications that have been adopted.

The determination of the corrections of the instrument for liquids other than water can be made by the individual, either by experiment or by reference to available data. If the apparatus be a vessel for delivering total volume a simple method of obtaining the correc- 
tion when using a special liquid is to weigh the empty vessel, weigh again containing only the residue after delivering water, and again containing the residue after delivering the liquicl. The liquid delivered is weighed roughly and the approximate knowledge thus gained of the density of the liquid suffices for a calculation of the small volume of the residne, and the difference between this volume and the volume of the water residue may be applied as a correction to the delivery capacity determined by water in the ordinary way. This disregards the difference caused by the effect of capillarity on the meniscus volume, mentioned later.

The relation between the nature of the liquid and the volume delivered by pipettes has been made the subject of a careful and extended investigation by Schloesser and Grimm. ${ }^{10}$ For the investigation transfer pipettes of IOO, 25, and Io cc were employed. The exact form and dimensions of the tips and delivery tubes are not described, and effects due to the different causes, namely, residue on the walls of the pipette bulb, residue on the walls of the delivery tube, and the residue in the tip cannot be differentiated. It cannot be concluded, therefore, that the results obtained with these pipettes would necessarily be duplicated with other pipettes of the same capacity but differing in form, although valuable information is afforded as to the general behavior of pipettes when employed for various liquids.

The concentration of the liquids of titration employed by these investigators was usually normal, but was tenth-normal where that concentration is the highest employed in titration. The adjustment of the concentrations was only approximate. The density was determined by hydrostatic weighing.

The surface tensions were for the most part determined at the Kaiserliche Normal-Eichungs-Kommission at a temperature of $\mathrm{I} 7^{\circ} \mathrm{C}$. The viscosities were taken from the tables of Landolt and Börnstein. The settings were made by bringing the base (center) of the meniscus to the line, except in the case of milk. The pipettes were allowed to empty themselves into a receiving vessel by free outflow, completed by touching the outflow nozzle to the wetted surface of the receiving vessel. There was 110 wait to allow

${ }^{10}$ Chemiker Zeitung, :30, pp. Io7 I to Io73; 1906. $22832-08-8$ 
Bullctin of the Burcau of Standards. [Vol.4, No.4.

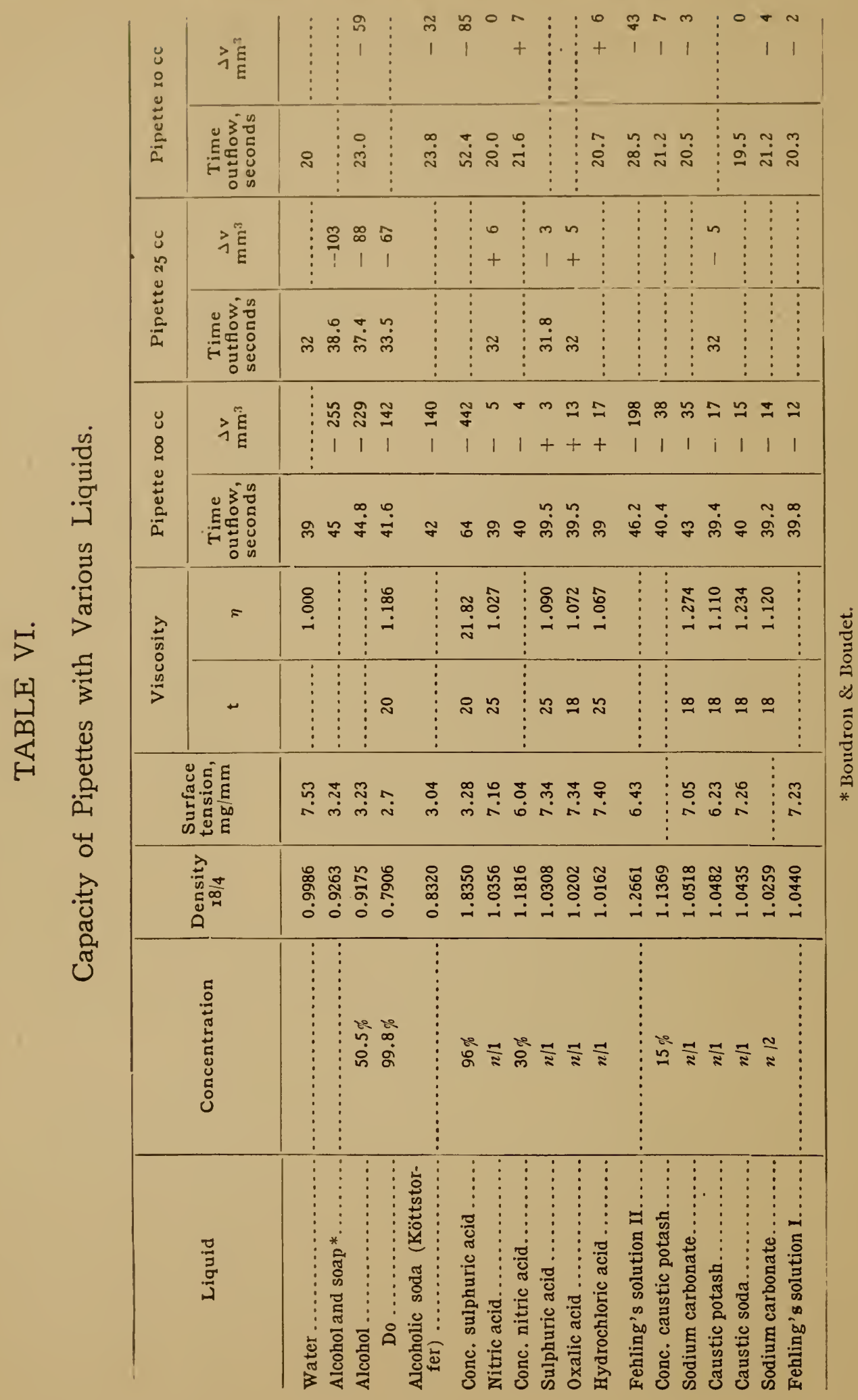




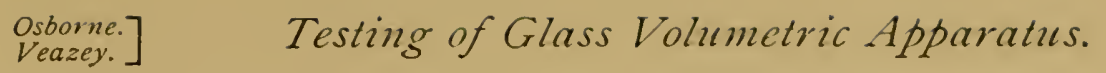

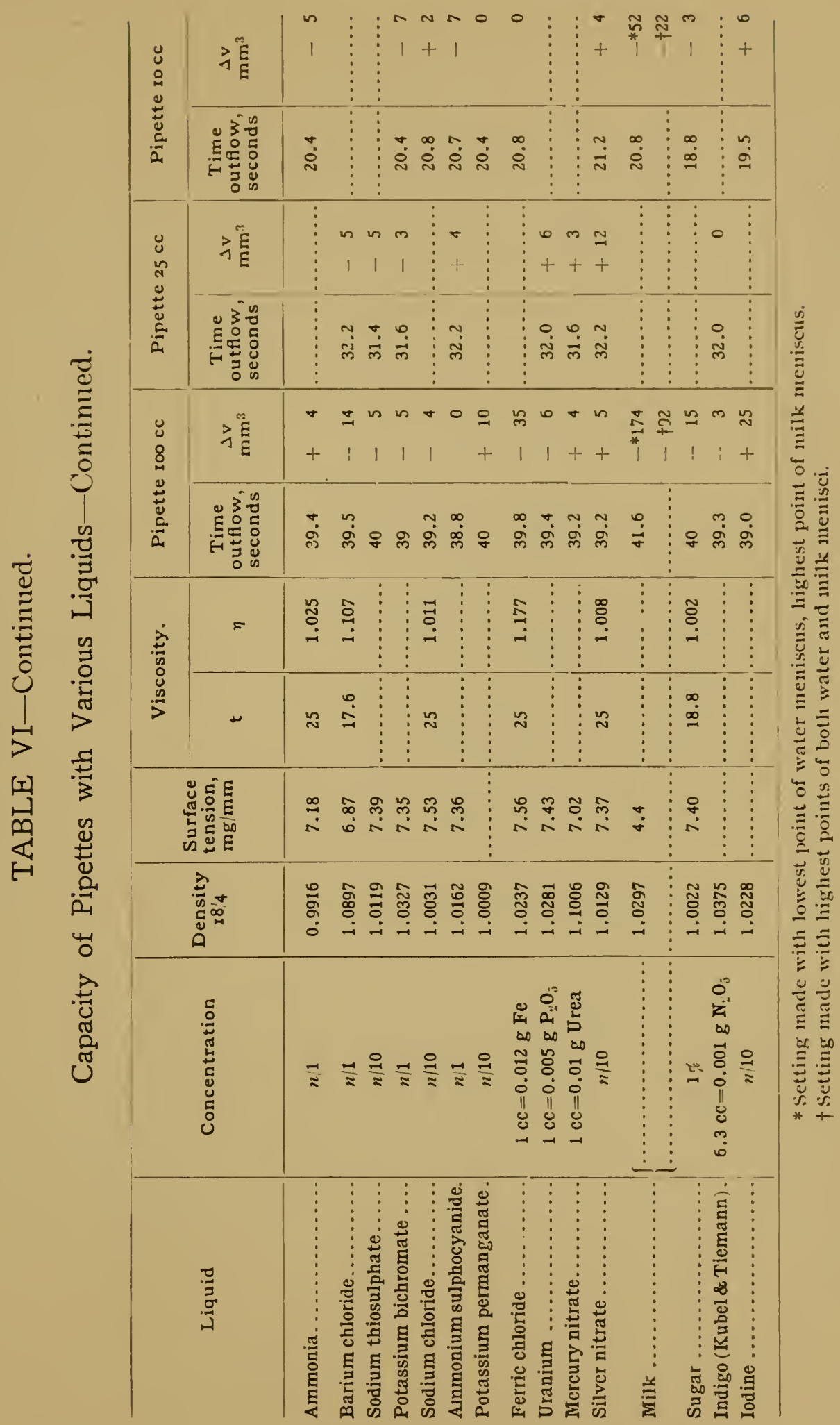


after-drainage. The mass of the liquid delivered was determined by weighing and making the appropriate corrections for buoyancy of the air. The volume was then known as the quotient of mass by density. The temperature of observation varied between $16^{\circ}$ and $19^{\circ} \mathrm{C}$. The results are given in the Table VI, in which $\Delta v$ signifies volume of liquid delivered minus volume of water delivered.

These results indicate that pipettes may be used interchangeably for solutions not exceeding normal concentration if the solutions have approximately the same capillary constant, ${ }^{11}$ as water and the ontflow time is observed to be the same as for water.

4. Effect of Temperature on Residue in Burettes and Pipettes.The effect of temperature on the volume delivered by pipettes and burettes has been investigated by Schloesser. ${ }^{12}$ The results of this investigation were as follows:

TABLE VII.

\begin{tabular}{|c|c|c|c|c|c|}
\hline \multicolumn{2}{|c|}{$\begin{array}{l}\text { Pipette ro cc. Outflow time } \\
20 \mathrm{sec} \text {. }\end{array}$} & \multicolumn{2}{|c|}{$\begin{array}{l}\text { Pipette roo cc. Outflow time } \\
39 \text { sec. }\end{array}$} & \multicolumn{2}{|c|}{$\begin{array}{c}\text { Burette } 50 \mathrm{cc} \text {. Outflow time } \\
52.5 \mathrm{sec} \text {. }\end{array}$} \\
\hline $\begin{array}{l}\text { Temperature. } \\
\text { oC. }\end{array}$ & R. & $\begin{array}{l}\text { Temperature. } \\
\text { o C. }\end{array}$ & R. & $\begin{array}{l}\text { Temperature. } \\
\text { oC. }\end{array}$ & R. \\
\hline 4.3 & 0.067 & 5.5 & 0.260 & 5.3 & 0.233 \\
\hline 11.5 & 0.067 & 10.8 & 0.224 & 12.6 & 0.205 \\
\hline 21.3 & 0.061 & 20.6 & 0.216 & 21.5 & 0.191 \\
\hline 29.9 & 0.062 & 30.6 & 0.197 & 29.8 & 0.191 \\
\hline
\end{tabular}

$\mathrm{R}$ in the above signifies the residue in cc of water after outflow. So far as can be judged from these data the temperature effect, aside from the expansion of the glass, is appreciable, but in most work negligible if the temperature be always between $\mathrm{I} 5^{\circ}$ and $30^{\circ} \mathrm{C}$. The effect in burettes whose outflow time conforms with the specifica-

${ }^{11}$ Hy the capillary constant or specific cohesion in this paper the quantity a $\mathrm{a}^{2}$ will be neant, which is defined by the equation

$$
a^{2}=\frac{2 T}{g s}
$$

in which $T$ is the surface tension in dyn/cm, $s$ is the density, and $g$ the gravity constant.

${ }^{12}$ Zs. für Analytische Cliemie, 1). 4r3; 1907. 
tions of this burean may be expected to be considerably less than for the burette employed by Schloesser. This will be more apparent after consideration of our own results on burette drainage.

5. Avoidance of Unnecessary Heat.-In the use of glass apparatus for measuring liquids the practice of heating to extraordinary temperatures, as in cleaning with hot water, should be avoided on account of the thermal after effect corresponding to the depression of zero in a thermometer. While for certain kinds of glass this effect may be negligible we have no assurance that it is so for all kinds of glass employed in volumetric apparatus, and it is well to avoid an unnecessary source of error.

\section{FLASKS AND CYLINDERS.}

1. Difference in Volume Delivered and Contained.-Graduated cylinders accepted for test must be marked "to contain," and are tested accordingly. When flasks and cylinders are used to deliver, they should be filled as when used to contain and be emptied by gradually tilting them until, when the continuous stream has ceased, they are almost vertical. After draining in this position for half a minute the drop should be removed by bringing the mouth of the flask or cylinder lightly into contact with the wetted surface of the receiving vessel.

Cylinders correctly graduated to contain within the allowed limits of error are in general correct to deliver within twice these limits of error when the delivery is made in the above manner.

This proposition has been established by determining the difference between the amount contained and the amount delivered for varions sizes of cylinders and for various intervals of each. The cylinders were of the ordinary dimensions, the ratio of diameter to length being approximately as I to 5 .

The cylinders were emptied in the manner described, with this difference, that each cylinder was allowed to drain one minute. The dry cylinder was counterpoised, filled to the point under test, emptied, and replaced upon the scalepan of the balance. The weight added to the tare to balance the cylinder gave the weight of water remaining. This amount is obviously the difference between the anount delivered and the amount contained. 
The maximun difference between the volume contained and the volume delivered occurs in every case when the interval under test is the total interval. The linits of error when the cylinder is used to contain are, however, the same for the total interval as for the sub-intervals. To show that the difference between the volume contained and the volume delivered is usually not greater than the limits of error when the cylinder is used to contain, the following comparison is sufficient:

TABLE VIII.

\begin{tabular}{c|c|c}
\hline Capacity of cylinder. & Limits of error. & $\begin{array}{c}\text { Difference contained and } \\
\text { delivered. }\end{array}$ \\
\hline $10 \mathrm{cc}$ & $0.6 \%$ & $0.35 \%$ \\
$25 \mathrm{cc}$ & $0.24 \%$ & $0.35 \%$ \\
$50 \mathrm{cc}$ & $0.2 \%$ & $0.20 \%$ \\
$100 \mathrm{cc}$ & $0.3 \%$ & $0.17 \%$ \\
$250 \mathrm{cc}$ & $0.48 \%$ & $0.12 \%$ \\
$500 \mathrm{cc}$ & $0.24 \%$ & $0.11 \%$ \\
$1000 \mathrm{cc}$ & $0.2 \%$ & $0.09 \%$ \\
\hline
\end{tabular}

Since the period of drainage was a full minute instead of a half minute, the above results would have less weight were it not that the effect of reducing the period of drainage to a half minute is much less than the limits of error with which we are dealing. This is shown by the investigation of W. Schloesser ${ }^{13}$ on the effect of varying the period of drainage of flasks used to deliver. Although his investigation deals with flasks it is to a sufficient extent applicable to cylinders.

2. Use of Special Liquids. - In the absence of more specific knowledge as to the use of flasks and cylinders to deliver liquids other than water it is best to avoid such use in measurements requiring precision. For flasks to contain, however, it is possible to calculate, providing we know the capillary constant of a liquid and the diameter of the neck of the flask, the correction to be applied to the capacity for water in order to obtain the capacity for that liquid. This correction is obviously the difference between the two meniscus vol-

${ }^{13} \mathrm{Zs}$. für Analytische Chemie, p. 403, I907. 
umes. By the meniscus volume is meant the volume of the meniscus above the liorizontal plane tangent to the base (center) of the neniscus.

Table IX is for use in this connection. It gives, for varions values of the specific cohesion and for various tube diameters, the quantity by which the corresponding meniscus volume is less than the normal (maximum) meniscus volume of pure water at $2 \mathrm{O}^{\circ} \mathrm{C}$.

The specific cohesion has already been defined.

Table $\mathrm{X}$ gives the meniscus volume of pure water at $20^{\circ} \mathrm{C}$, , having the normal surface tension $72.5 \mathrm{dyn} / \mathrm{cm}$. The meniscus volume corresponds therefore to a specific cohesion of $14.82 \mathrm{I} \mathrm{mm}^{2}$.

These tables were derived by the aid of the tables of Bashforth and Adams. ${ }^{1 \pm}$ It was found convenient to interpolate graphically in making Table IX. The maximum error in this table probably does not exceed $0.00 \mathrm{I}$ cc. Table $\mathrm{X}$ was used in making Table IX. The maximum error probably does not exceed $0.0002 \mathrm{cc}$. The table is not immediately useful in the work dealt with in this paper, so that the values are given as derived in order to preserve their accuracy.

\section{TRANSFER PIPETTES.}

A slight change has been made in the regulation as to time allowed for after-drainage in transfer pipettes. Instead of waiting I 5 seconds after outflow ceases, as formerly, and then removing the accumulated excess at the tip, the wait of 15 seconds is omitted and the excess at once removed by touching the wet surface of the receiving vessel. This is in accordance with the recommendations of the International Committee on Analyses, Rome, I906.

1. Design.-A question which deserves some study and investigation is that of the extent to which the form and dimensions of transfer pipettes influence their behavior with various liquids. It should be possible to predict their behavior with certainty when the properties of the liquids are known.

Recommendations as to shape of tips of burettes and pipettes have been included in the specifications under the head of special requirements. These recommendations are based on observation of the performance of tips of various forms and indicate the forms consid-

${ }^{14}$ Capillary Action, Cambridge, $\mathrm{IS}_{3}$. 
TABLE IX.

Defect in Meniscus Volume.

\begin{tabular}{|c|c|c|c|c|c|c|c|c|c|c|c|}
\hline \multirow{2}{*}{$\begin{array}{c}\text { Tube } \\
\text { diameter }\end{array}$} & \multicolumn{11}{|c|}{ Specific Cohesion in $\mathrm{mm}^{2}$} \\
\hline & 14 & 13 & 12 & II & 10 & 9 & 8 & 7 & 6 & 5 & 4 \\
\hline $4 \mathrm{~mm}$ & .000 & .000 & .000 & .000 & .000 & .000 & .001 & .001 & .001 & .001 & .001 \\
\hline 5 “ & .000 & .000 & .000 & .001 & .001 & .001 & .001 & .002 & .002 & .003 & .003 \\
\hline 6 “ & .000 & .001 & .001 & .001 & .002 & .002 & .003 & .004 & .004 & .005 & .007 \\
\hline $7 ،$ & .000 & .001 & .001 & .002 & .003 & .004 & .005 & .006 & .007 & .009 & .012 \\
\hline $8 ،$ & .001 & .001 & .002 & .003 & .005 & .006 & .008 & .010 & .012 & .015 & .018 \\
\hline 9 ، & .001 & .002 & .004 & .006 & .007 & .010 & .012 & .015 & .018 & .023 & .027 \\
\hline 10 “ & .001 & .004 & .006 & .008 & .011 & .014 & .018 & .022 & .027 & .032 & \\
\hline $11 ،$ & .002 & .005 & .008 & .012 & .016 & $\cdot 020$ & .024 & .030 & .036 & & \\
\hline 12 " & .003 & .007 & .011 & .016 & .021 & .025 & .032 & .040 & & & \\
\hline 13 & .004 & .009 & .014 & .020 & .026 & .033 & .041 & & & & \\
\hline $14 "$ " & .005 & .011 & .017 & .025 & .033 & .042 & & & & & \\
\hline $15 "$ & .006 & .013 & .022 & .030 & .041 & & & & & & \\
\hline 16 “ & .007 & .016 & .027 & .037 & & & & & & & \\
\hline
\end{tabular}

TABLE X,

Meniscus Volume of Pure Water $-\left(\mathrm{a}^{2}=0.14821 \mathrm{~cm}^{2}\right)$.

\begin{tabular}{|c|c|c|c|}
\hline Radius of Tube & Meniscus Volume & Radius of Tube & Meniscus Volume \\
\hline $0.0944 \mathrm{~cm}$ & $0.0009 \mathrm{~cm}^{3}$ & $0.6494 \mathrm{~cm}$ & $0.1551 \mathrm{~cm}^{3}$ \\
\hline 0.1311 ، & 0.0023 & 0.6720 & $0.1669 \cdots$ \\
\hline 0.1796 “ & 0.0056 & 0.6917 “ & 0.1774 ، \\
\hline 0.2410 " & 0.0129 “ & 0.7171 & 0.1912 “ \\
\hline 0.2829 “ & 0.0200 & 0.7389 & 0.2033 \\
\hline $0.3150 "$ & 0.0267 “ & 0.7579 " & 0.2139 \\
\hline 0.3634 " & 0.0388 & 0.7800 & 0.2265 \\
\hline 0.4149 “ & 0.0544 “ & 0.7993 “ & 0.2377 《 \\
\hline 0.4639 ، & 0.0716 “ & 0.8164 “ & 0.2476 \\
\hline 0.4924 “ & 0.0827 “ & 0.8317 ، & 0.2566 “ \\
\hline 0.5235 & 0.0955 “ & 0.8457 & 0.2648 \\
\hline 0.5492 " & 0.1068 “ & 0.8553 & 0.2705 “ \\
\hline 0.5904 “ & 0.1258 “ & 0.8615 ، & 0.2742 《 \\
\hline 0.6227 & $0.1416 “$ & & \\
\hline
\end{tabular}


ered most desirable. Reasonable variation in the form of tips will be allowed, but instruments in which the construction shows maniifest disregard for correct form and good workmanship will not be tested.

\section{BURETTES AND MEASURING PIPETTES.}

1. Burette Drainage and Outflow Time.-Drainage in burettes is considered by W. Scliloesser ${ }^{15}$ in his valuable discontse on the testing of volunetric apparatus at the Kaiserliche Normal-EichnngsKommission. His results clearly indicate a relation between the duration of the ontflow and the amount and distribution of the drainage, but do not seem to fully indicate the relation of these variables, nor the influence of the actual length of tube emptied.

It seemed desirable to study somewhat further the characteristics of the drainage under various conditions, and for this purpose experiments were made at this bureau in the summer of 1904 .

Two tubes were used of about 8 and I $4.6 \mathrm{~mm}$ mean inside diameter, respectively. These are about the extreme diameters used for burettes of from ro to IOO cc capacity. Using the tubes in the manner of burettes, intervals of from 5 to $60 \mathrm{~cm}$ in length were emptied at various rates. When the outflow was stopped at the end of any interval the meniscus was shaded and its motion observed at frequent intervals of time by means of a horizontal micrometer microscope of long focus. The first observation was made Io seconds after stopping the outflow. The temperature of observation varied from $23^{\circ} \mathrm{C}$ to $27^{\circ} \mathrm{C}$.

The accompanying curves, Figs. 6 to I 7 , exhibit the results of the observations. They show the rise of the meniscus above the first observed position for various times after stopping the outflow.

The curves indicate certain characteristics in the behavior of the water residue which have a bearing on the choice of ontflow time. Thus the rate of drainage or afterflow is greater the more rapid the descent of the meniscus. A large afterflow can arise only from a heavy film of liquid left behind a falling meniscus-that is, from a heavy residue. Therefore the residue is greater the more rapid the descent of the meniscus. 
By- liniting the rate of ontflow the residue and the afterflow may be made negligibly small. 'The system of curves considered with reference to the rate of ontflow enables a choice of ontflow rate which shall sufficiently limit the afterflow. For the maximum or initial rate a value was sought which should render the residue and drainage so small that the volume delivered should be independent of such variations in manipulations as are often found necessary by the chemist. Reference to the curves shows that for an initial rate of 0. $7 \mathrm{~cm}$ per second the maximum drainage from any interval emptied which occurs during the first two minutes after stopping outflow is about $0.05 \mathrm{~mm}$. This initial rate was selected, and the specifications in regard to time of outflow of the total graduated length were so chosen that on burettes of customary proportions the maximum initial rate should not exceed $0.7 \mathrm{~cm} / \mathrm{sec}$.

Reducing the initial rate of outflow decreases the effect on the volume delivered of stops at intermediate points. The effect of stops can best be determined by trial in each instance, since it seems likely that stops sometimes increase and sometimes decrease the volume delivered. The tendency for decrease in volume delivered is due to heavier residue at the points where the descent of the meniscus has been retarded.

The prescribed minimum time of ontflow increases more rapidly the greater the length of graduated interval. Consequently, burettes should be made as short as the minimum length of a single subdivision will permit, in order to economize time without loss in accuracy.

The danger of clogging the tip, which has been mentioned as an objection to the small size of the orifice required by these specifications, is one which should not cause a careful observer much concern.

As an example of the necessity for restricted time of outflow a curve, Fig. I8, is given showing the apparent capacity corresponding to various ontflow times of a $5 \mathrm{O}-\mathrm{cc}$ burette whose graduated length is $63 \mathrm{~cm}$. It is readily seen that such variations in the time of outflow, as often occur in practice, have a large effect if the outflow time is much less than the specifications permit. If the outflow time of the burette were 65 seconds, increasing from this minimum by one minute the time consumed in making a titration would 
The curves on this sheet, Figs. 6 to 17, show the drainage observed in wo burette tubes when various linear intervals are emptied at certain rates. The tabulated initial and average rates represent the speed at which the meniscus descends the tube while emptying.

Bull. Bur. of Standarc.

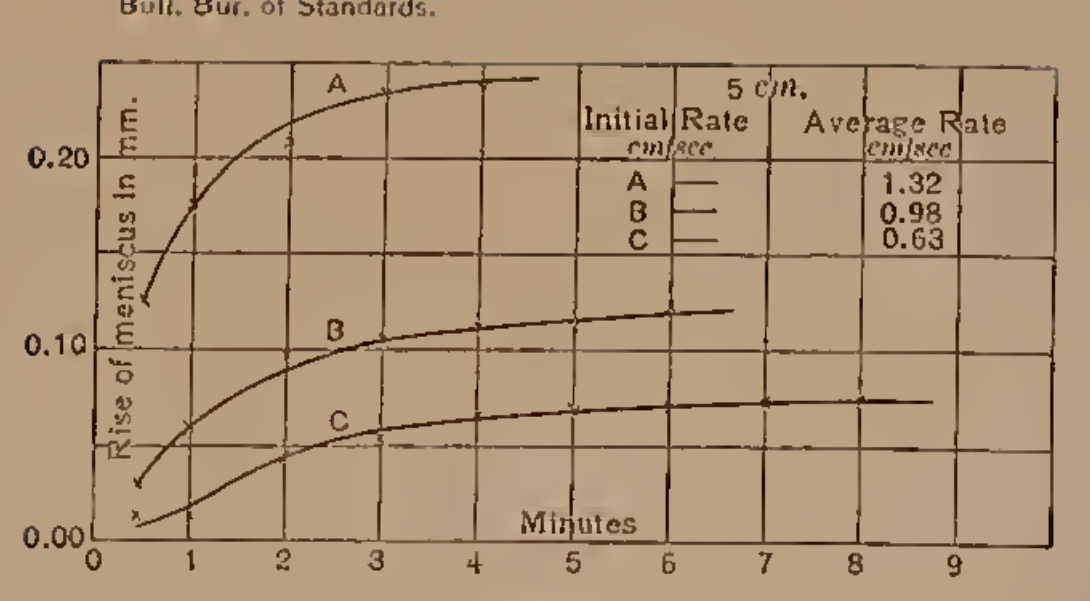
Fig. 6.
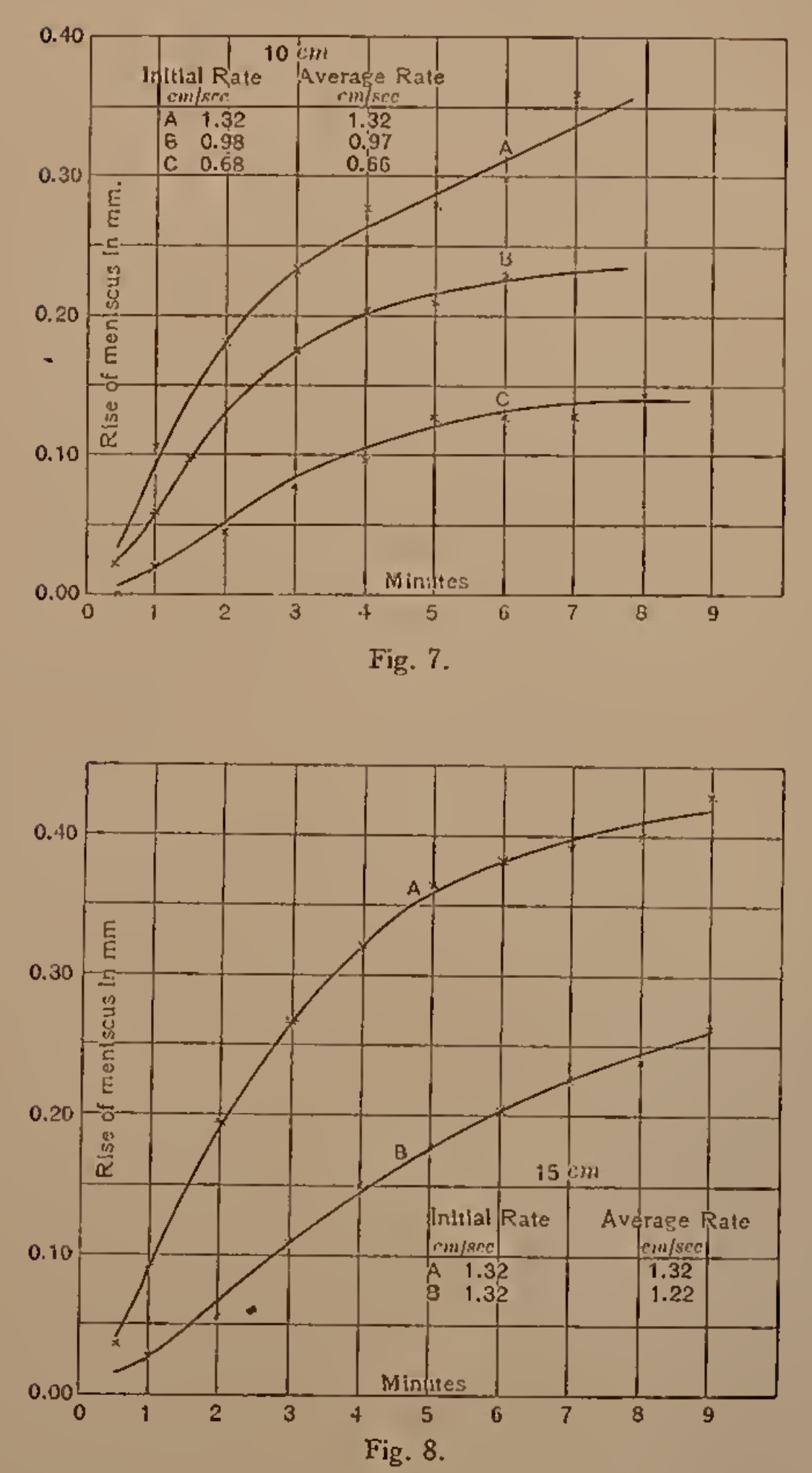
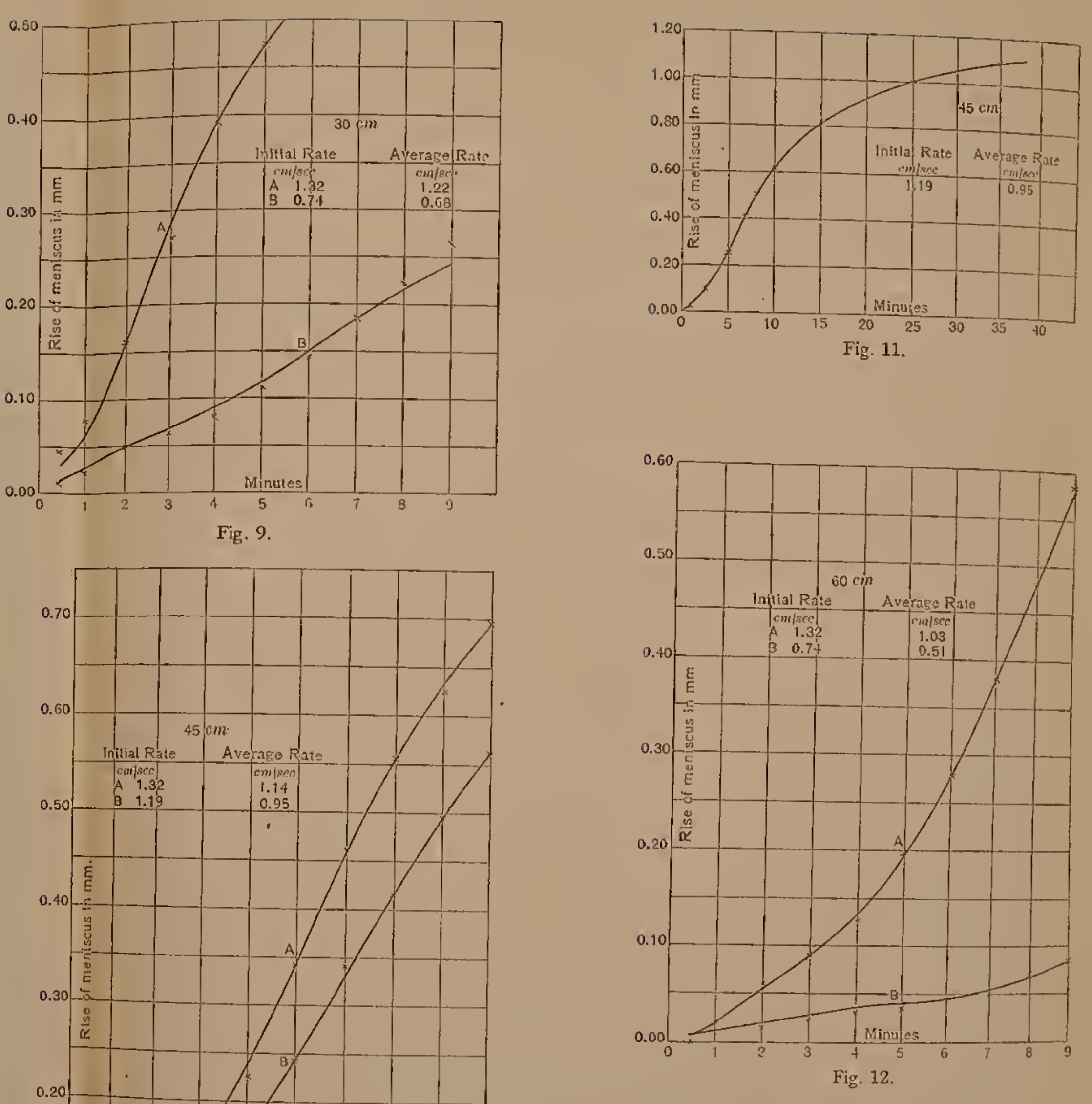

Fig. 12

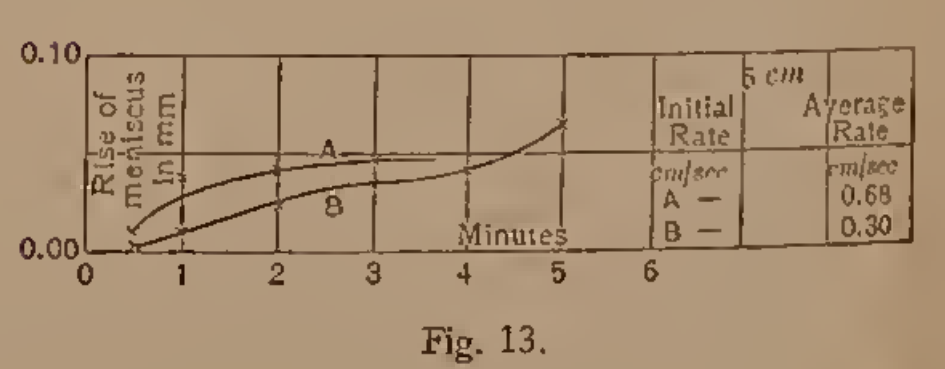

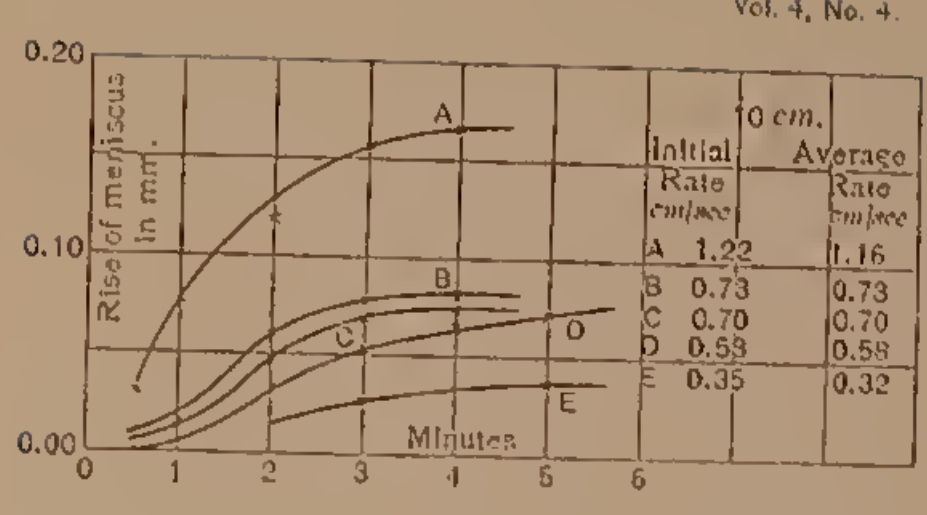
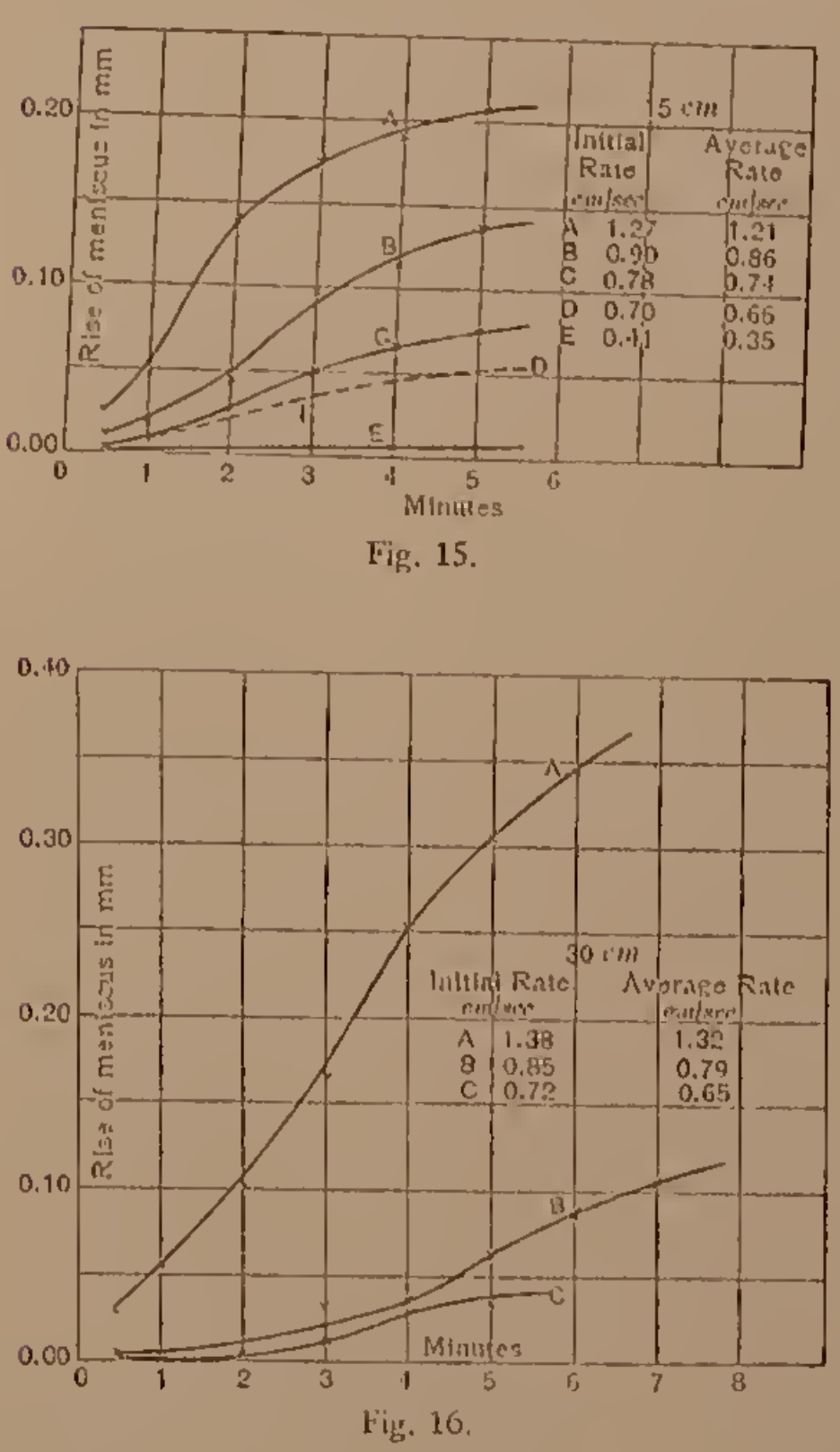

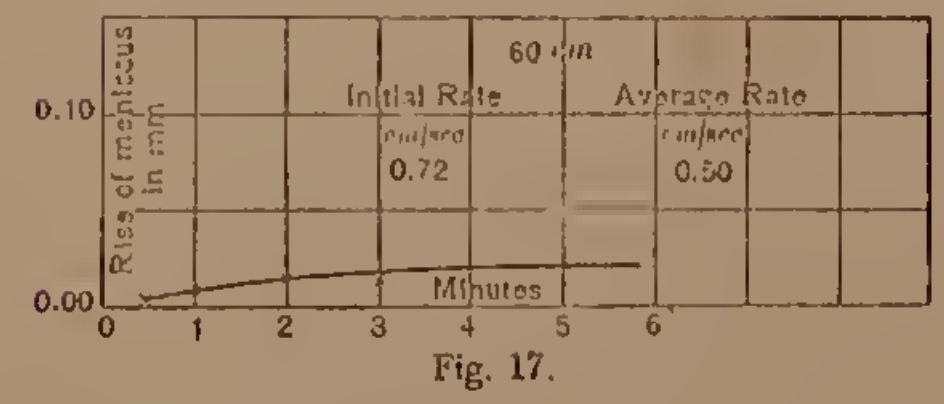


cause an increase of about $0.05 \mathrm{cc}$ in the volume delivered, as much as the permissible error for this size of burette.

2. Use of Special Liquids. - The use of burettes to measure liquids other than water differs from the similar use of transfer pipettes, since the uniform dianeter of the burette renders the measurements less dependent on the capillary properties of the liquids used. 'The effect of viscosity, however, is quite as apparent as in pipettes, since

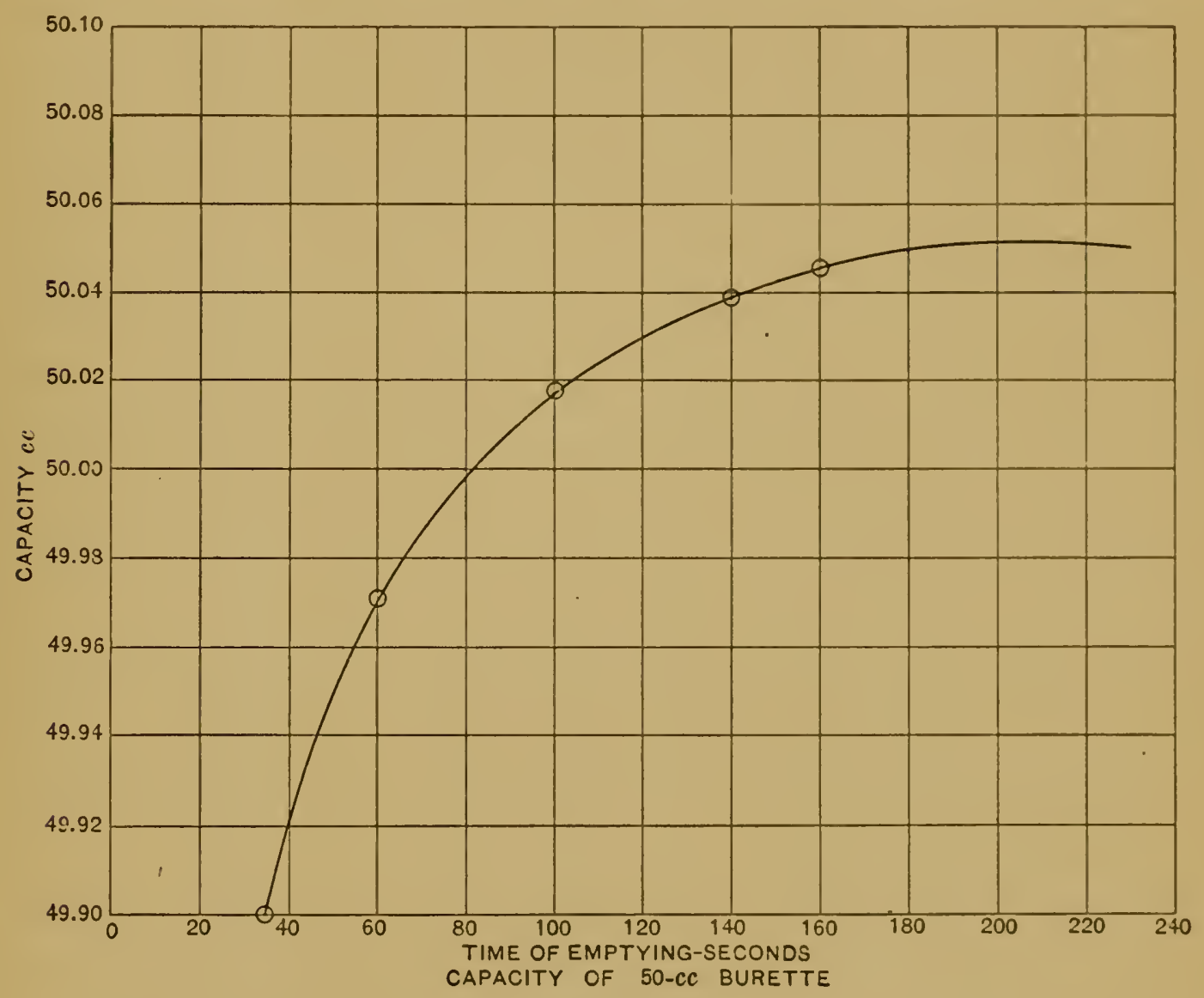

Fig. 18.

this property is one of the most inportant factors in determining the amount and movement of the residue when emptying a burette. It is apparent that liquids of approximately the same viscosity and density as water may be measured without error. Hence burettes may be used with confidence for liquids of about the density of water and giving a normal outflow time.

If with any liquid the outflow time is observed to differ appreciably from the normal it is not to be assumed that the capacity of the 
burette to measure that liquid is the same as for water and it is best to retest the burette with the liquid at several points.

3. Calibration.-In using burettes for precise work the chemist probably more often uses the intervals beginning at the zero graduation than those starting at intermediate points. There is a difference in the effective capacity of the intervals depending on how they are nsed, although if the outflow is made sufficiently slow this difference is generally quite small.

The calibration may be made using either successive intervals or those beginning at zero. For the purpose of determining the quality of the instrument the latter is preferable since it avoids cumulative error due to summation, as pointed out by Schloesser. ${ }^{16}$

In the manufacture of burettes it is important that the subdivision as well as the calibration be carefully performed. Several examples of faulty subdivision have been observed, among which several from the same maker (not domestic) showed such similar defects as to leave no doubt of systematic error in its production. One such example is shown on Fig. I9, which by a curve represents the cor-

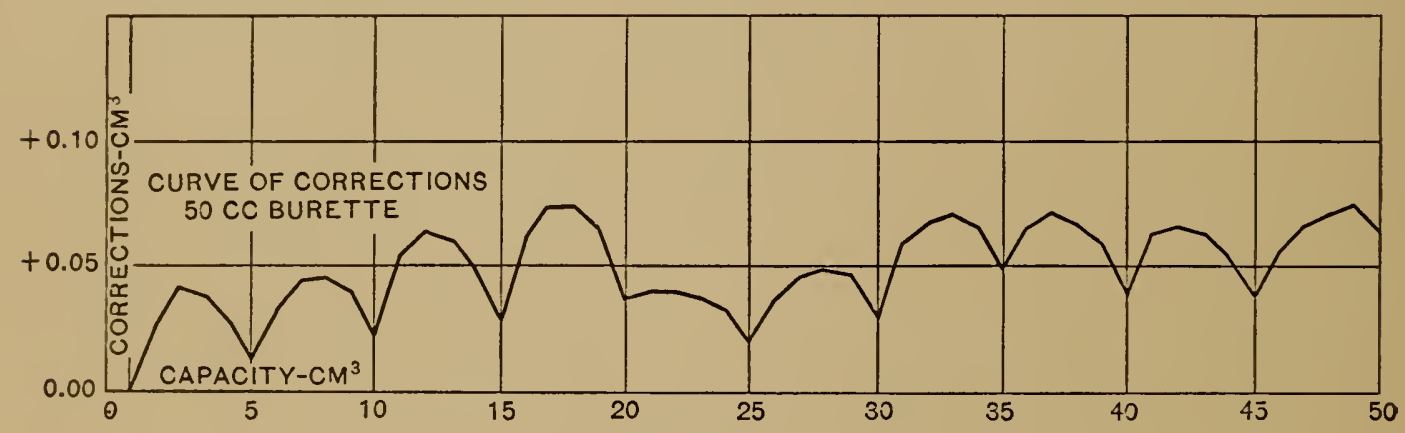

Fig. 19.

rections to the indicated capacities of a burette determined at every cubic centimeter. It is apparent that a burette with graduation of this kind is unfit for precise use. Furthermore, too much dependence must not be placed on calibrations at a few points. If the subdivisions are of uniform or uniformly varying length, intermediate corrections may be obtained by interpolation. The most preferable burettes are those in which the caliber is sufficiently uniform to permit uniformity of the subdivisions.

In regard to the arrangement of the division and subdivision of the intervals, attention may be called to advantages of interrupted 
or partial subdivision with portions enlarged into bulbs for use in cases where subdivision of the entire interval is not required. The advantages of this form of construction are gain in compactness, decrease in drainage, permitting rapid outflow, and economy of labor in calibration.

In regard to the arrangement for control of outflow, the use of delivery tips attached by rubber tubing and control of outflow by pinchcock (Mohr burette) is to be avoided in accurate work on account of the errors caused by the stretch of the rubber. The specifications exclude this type of burette. It is suggested that where lubricated glass stopcocks are undesirable measuring pipettes be employed in a manner similar to that described and illustrated under the head of methods of testing transfer pipettes.

4. Measuring Pipettes.-The principles which have been discussed in the preceding pages in reference to burettes are equally applicable to measuring pipettes. Since, however, the same precision is not ordinarily attainable in their use as with burettes, owing to the less complete control of the outflow, linits of error have been permitted twice as great as for burettes. The permissible maximum length graduated has been limited to $35 \mathrm{~cm}$, and also the permitted outflow time has been changed to correspond with that for burettes of similar graduated length instead of that for transfer pipettes of the same capacity. These regulations do not permit so frequent subdivisions on the larger pipettes as on burettes of the same capacity, but greater length; but the greater convenience of the shorter pipettes and the advantage of reduced drainage should quite compensate for whatever loss in precision is caused by the less frequent subdivisions.

5. Limits of Error.-The limits of error are the same for both total and partial capacities of any burette or measuring pipette. For example, on a $50-\mathrm{cc}$ burette the error must not exceed $0.05 \mathrm{cc}$ for any interval starting at the zero point for continuous emptying. Further, the errors of intermediate intervals, as determined by differences of errors found in intervals beginning at zero, must not exceed $0.05 \mathrm{cc}$. Thus, if the error of the interval o to $2 \mathrm{O} \mathrm{cc}$ is $+0.02 \mathrm{cc}$ and the error of the interval o to $40 \mathrm{cc}$ is $-0.05 \mathrm{cc}$, the error of the interval $2 \mathrm{O} \mathrm{cc}$ to $4 \mathrm{Occ}$ is reckoned $-0.07 \mathrm{cc}$ and the instrument is rejected. 


\section{METHODS OF TESTING.}

1. Preliminary Examination.-Apparatus submitted for test is first examined as to its conformity with the specifications. This examination determines the following items: general quality and workmanship, correctness of inscriptions, correctness of design and proportions, regularity in spacing of subdivisions, outflow time, etc.

If the apparatus complies with the specifications in other respects a determination of the capacity is made either to determine its fitness for the precision stamp or to obtair data for a certificate of capacity.

2. Methods of Cleaning Apparatus. - The liquids usually employed in preparing apparatus for test are concentrated solution of caustic soda in 95 per cent commercial alcohol, concentrated or fuming sulphuric acid, water, and alcohol. The caustic soda solution usually removes contaminations if left in the apparatus several hours, and is ordinarily employed for flasks. For badly contaminated apparatus the fuming sulphuric acid is more effective, and for small instruments, pipettes, and burettes, and all cases where haste is necessary the acid is found most expeditious.

After the use of the soda or acid the apparatus is thoroughly washed in clean water. If for immediate use it is rinsed with alcohol and dried by an air blast. No method has been found for cleaning apparatus such that drying leaves the apparatus free from contamination. If the apparatus is to deliver it is not dried, and in other cases the standard of cleanliness sought is the condition which will permit wetting of the entire interior of the apparatus by a continuous layer of water.

3. Measurement of Capacity.-The capacity of instruments to deliver is at present generally tested at this bureau by weighing the water delivered. Instruments to contain are sometimes tested by weighing their contents, but usually by filling them from a special measuring pipette.

(a) Testing Flasks by Direct Measurement.-Flasks are tested by filling them from a standard pipette whose lower stem is graduated to enable a direct reading of the volume of liquid delivered. The arrangement used in testing roo cc flasks is shown in fig. 20. It permits the testing of long-necked flasks and graduated cylinders without placing the standard pipette at an inconvenient height. 


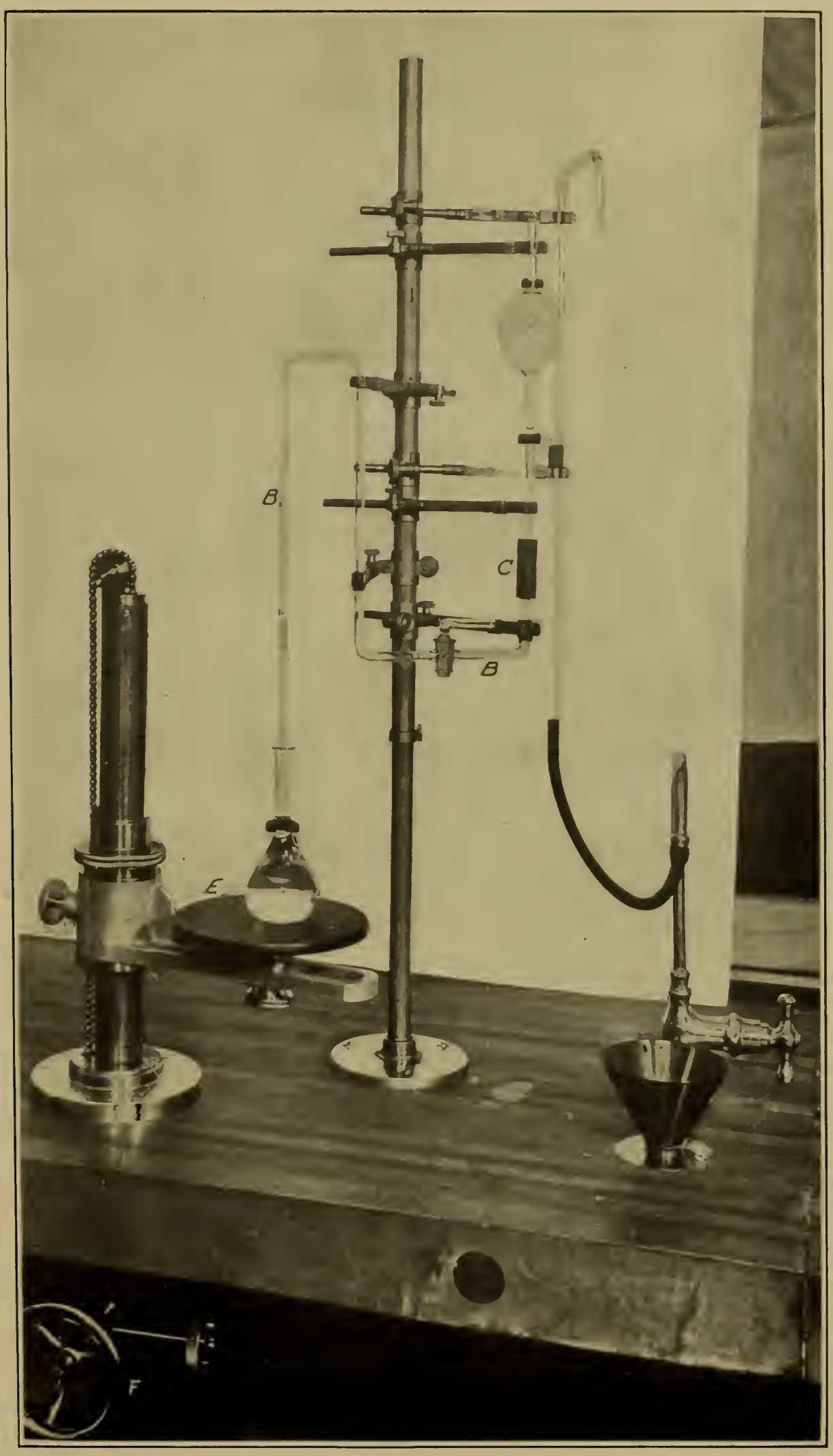

Fig. 20. 
The standard pipette is inserted into a heavy rubber connection $\mathrm{C}$. The delivery nozzle meets the connecting tube $B$ in a ground joint.

The pipette is filled through a glass nozzle, which is connected to a water fancet as shown in the illustration and is directed into the top of the pipette. The pipette is filled to the top, the nozzle is swung aside, and by opening the stopcock the meniscus is slowly lowered to the zero mark. Excess of water is then removed from the outflow nozzle, and the flask to be tested is placed on the platform $\mathrm{E}$ immediately under the ontflow nozzle. The platform is raised by turning the wheel $\mathrm{F}$ until the outflow nozzle is just inside the neck of the flask. The stopcock is opened wide and the flask rotated to wet the entire neck, and the flask is then raised until the nozzle is from I to $2 \mathrm{~cm}$ above the mark. Before completing the filling of the flask it is removed and the contents shaken as directed in the rules for manipulation. The filling is completed with the tip in contact with the wetted wall I to $2 \mathrm{~cm}$ above the mark. The meniscus in the flask is finally brought to the mark by breaking contact of the tip with the wetted surface.

The standard pipette is read at the end of its normal outflow time, plus 5 seconds. The pipette reading plus the instrumental correction is the capacity of the flask at the standard temperature of the pipette-that is, $20^{\circ} \mathrm{C}$. The object of shaking the water is to disperse the contaminations and thus produce a meniscus of normal volume. This manipulation reproduces the conditions of ordinary use. If the test is to merely ascertain whether the capacity is within the allowed limits of error, this detail is omitted unless the error is too near the limit to allow discrimination, in which case a retest is made. The magnitude of the possible error due to contamination has already been indicated in the previous discussion of variation in capacity of flasks.

This method of testing flasks obviates observations of temperature and weight and the calculations required in their reduction to equivalent volume, while it affords equal accuracy if care is observed. The method assumes that the temperature of the water is the sane in the pipette and in the flask and that the coefficients of expansion of the two vessels are nearly equal. No large systematic error is peculiar to the volumetric method except, under very unfavorable conditions, this error of temperature. 
'The pipettes used for this purpose at this bureau are interchangeable, it being only necessary to employ a nozzle of the proper size in order to use any pipette with the holder and outflow tube.

The use of standard graduated pipettes for determining the capacity of flasks has been described by Morse and Blalock, ${ }^{18}$ and the method described above merely introduces certain details of refinement adapting it to the immediate requirements of the testing laboratory.

(b) Testing Flasks, Pipettes, and Burettes by Weighing.-Although to economize time, flasks are usually tested at this bureau by direct measurement, as described above, they may also be tested, with equal accuracy, by weighing. This test consists in filling and observing the temperature and weight of the water contained. The manner of weighing is described later.

In testing either transfer pipettes or measuring pipettes the pipette is clamped in a vertical position. The pipette is filled by suction from a beaker of water. The pipette is first filled and emptied back into the beaker to bring the pipette to the temperature of the water and also to observe the time of outflow. The temperature of the water in the beaker is then observed. The pipette is again filled and is emptied into the weighing flask. The method of weighing is described later.

The manner of holding and manipulating pipettes at this bureau will be explained with the aid of the accompanying photograph, Fig. 2I. The end of the suction tube is inserted in the rubber connection $\mathrm{C}$ and is held in position by a clamp lower on the tube. The filling device consists of a bent capillary of about $2 \mathrm{~mm}$ diameter, the end of which is also inserted in the rubber connection C. This capillary terminates in a well-ground stopcock B, which is fitted with a long handle. To permit nice control of the opening, the movable part of the cock is provided with tapering nicks extending from the edge of the perforating hole for several millimeters of the circumference on opposite ends and opposite sides of the hole. The stopcock is lubricated with graphite from a soft pencil, since the use of grease would prevent nice control of the air flow. The flask $F$ is connected by the tube $\mathrm{V}$ with a vacumm pipe. 


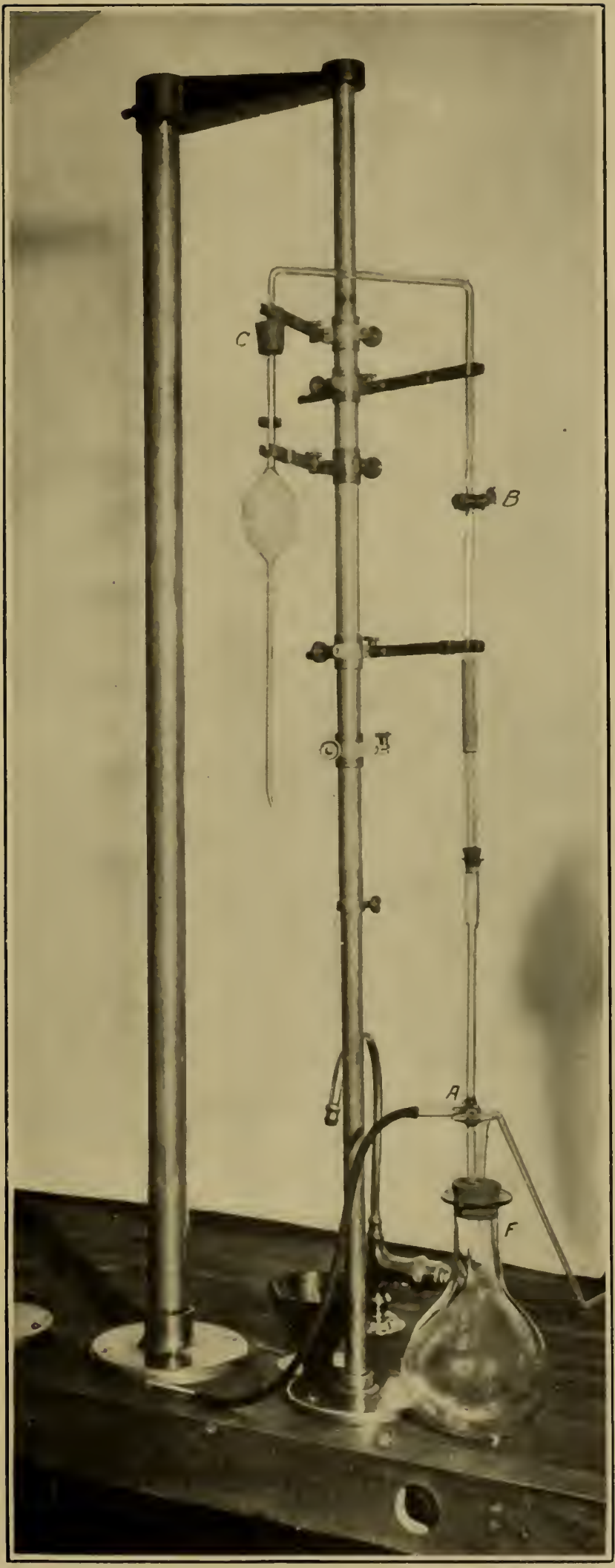

Fig. 21. 
To fill the pipette, the two-way cock $\mathrm{A}$ is turned to connect the evacuated flask $F$ with the stopcock B. A beaker of water is so held that the tip of the pipette is submerged, and by partially opening the stopcock $B$ the pipette is rapidly filled. The two-way cock $A$ is then turned to shut off the vacuum and admit atmospheric pressure. The outside of the tip is wiped with clean filter paper if necessary to remove adhering drops. A clean beaker is held touching the tip and the cock B again carefully opened until the meniscus descends slowly to the mark. The cock is closed and the beaker removed. The emptying is accomplished by fully opening the cock B.

This arrangement is used for both transfer and measuring pipettes. It has been found that settings can be made with almost the same precision as with burettes if the tip is separated from the receiving vessel immediately after closing the cock. The advantage of filling by automatic suction is greatest in the larger pipettes, where it avoids fatigue and waste of time.

Burettes are mounted for test with clamps on firm uprights. They are filled through a glass nozzle which is connected to a distilled water faucet and is directed into the top of the burette. The burette is filled and emptied into a beaker. The temperature of the water delivered is observed; the burette is again filled, the nozzle swung aside, and the interval to be tested is emptied into a weighing flask. The method of weighing is described later.

Burettes and measuring pipettes are tested in intervals beginning with the zero mark.

In observing the apparent weight in air of the water contained by a flask, two weighings of the flask are made, the first before receiving the water whose volume is required, and the second after the addition of the water. The rubber stopper for closing the flask is included in both weighings, and when the temperature is observed immediately before weighing, the thermometer is also included, being held by inserting its upper end into the stopper.

The flask is hung from the left balance hook, leaving the pan free to receive weights. On the right pan is placed a weight heavier than the filled flask. This weight is not changed during any determination. The sensibility of the balance is thus unchanged, and is usually so adjusted that the milligrams are indicated directly on the 22832-08-9 
scale by the pointer. Sufficient weights are placed on the left pan to secure equilibrium and their amount observed. The difference between two snccessive observed weights is the apparent weight of the water added.

When several volumes of water are to be weighed, as in calibrating a burette or testing transfer pipettes, a flask sufficiently large is used to permit these volumes to be added to the flask successively, the weight being observed between each addition. The balances used are provided with special mechanism designated as the Rueprecht system. This mechanism furnishes three different sensibilities such that the pointer indicates on the scale, in division units of IOO, IO, or I $m$ m as desired, the defect in counterpoise, and so avoids the nsual approximation by trial. The small weights are manipulated without opening the balance case.

The buoyancy constant; that is, the difference between the mass and apparent weight of unit volume of water, is determined by observations of temperature, pressure, and humidity, and the use of suitable tables. At this laboratory the buoyancy constant is dete1mined directly by weighing in air a hollow sealed glass bulb whose volume is about $900 \mathrm{cc}$. The mass of this bulb is such that when the bulb and a brass weight of equal mass are upon opposite sides of a balance, the mass of the additional weights on the bulb side necessary to secure balance; that is, the difference between the mass and apparent weight of the bulb, equals the buoyancy constant for one liter as defined above.

(c) Calculation of Capacity.-In measurement of capacity by weighing water the following quantities are obtained by observation:

Nominal capacity; that is, volume indicated by instrument being tested.

Temperature of water.

Apparent weight of water in air; that is, mass of weights required to counterpoise the water in air.

Buoyancy constant.

The degree of precision required determines whether or not observation of the buoyancy constant is necessary.

The quantity sought is the actual capacity of the instrument at the standard temperature; that is, $20^{\circ} \mathrm{C}$. The capacity at the 
observed temperature; that is, volume of water weighed is first calculated.

For calculating the volume of water weighed three methods are here given and the special application of each indicated.

'The symbols employed are as follows:

\section{Quantities Observed.}

$V=$ nominal capacity.

$t=$ temperature of water.

$a=$ apparent weight in air of water.

$b=$ buoyancy constant.

Quantities Obtained from Tables.

$d_{t}=$ density of water at $t^{\circ} \mathrm{C}$.

$M=$ mass of water having a volume $V$ at $t^{\circ} \mathrm{C}$.

$A=$ apparent weight in air of water having volume $V$ at $t^{\circ} \mathrm{C}$.

\section{Quantities Calculated.}

$v=$ volume of water at $t^{\circ} \mathrm{C}$.

$C=$ capacity of instrument at standard temperature, $20^{\circ} \mathrm{C}$.

In all cases where precision is desired the following formula serves,

$$
v=\frac{a}{d_{t}-b}
$$

$d_{t}$ is obtained from Table XII, using temperature of water. $b$ may be observed directly or obtained from Table XI, using temperature and barometer observations.

Where $V$ is a round number, use of the following approximate formula simplifies the calculation.

$$
v=V+a+V b-M
$$

$M$ is obtained from Tables XIII to XVIII, using temperature of water. $b$ may be observed directly or obtained from Table XI, using temperature and barometer observations. Where $v-V$ is n11111erically less than $\frac{I}{\mathrm{IOOO}} v$ the approximation employed in this formula causes no error greater than $\frac{I}{200000} v$. 
Where $l$ is a round number and the buoyancy constant is not observed the following formula is used:

$$
v=V+a-A
$$

$A$ is obtained from Table XIX, using temperature of water. Formula (3) is equal in accuracy to formula (2).

After calculating $v$ by one of the above methods, $\mathrm{C}$, the capacity of the instrument at $20^{\circ} \mathrm{C}$ is calculated by the formula (4), $\mathrm{C}=v+$ va $(2 \mathrm{O}-t)$.

Calculated values of $v a(2 \mathrm{O}-\mathrm{t})$ are given in Table XX.

(d) Tables Used in Calculating Capacity.-For use in making measurements of capacity or volume by weighing, a number of tables are inserted to supply data.

Table XI gives the difference in milligrams between the mass and the apparent weight of I cubic centimeter of water weighed with brass weights $(d=8.4)$ in air at various temperatures and barometer readings (unreduced). A humidity of 50 per cent is assumed. This quantity is $b$, the buoyancy constant used in formulas (I) and (2).

TABLE XI.--Buoyancy Constant $\mathrm{mg} \mathrm{cm}^{3}$.

\begin{tabular}{|c|c|c|c|c|c|}
\hline & \multirow{2}{*}{ Pressure } & \multicolumn{4}{|c|}{ Temperature in Degrees Centigrade } \\
\hline & & 15 & 20 & 25 & 30 \\
\hline \multirow{13}{*}{ 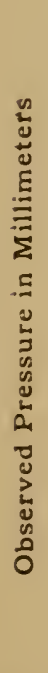 } & 720 & 1.017 & 0.998 & 0.979 & 0.960 \\
\hline & 725 & 1.024 & 1.004 & 0.985 & 0.967 \\
\hline & 730 & 1.031 & 1.011 & 0.992 & 0.973 \\
\hline & 735 & 1.038 & 1.018 & 0.999 & 0.980 \\
\hline & 740 & 1.045 & 1.025 & 1.006 & 0.987 \\
\hline & 745 & 1.052 & 1.032 & 1.013 & 0.994 \\
\hline & 750 & 1.059 & 1.039 & 1.020 & 1.000 \\
\hline & 755 & 1.067 & 1.046 & 1.027 & 1.007 \\
\hline & 760 & 1.074 & 1.053 & 1.034 & 1.014 \\
\hline & 765 & 1.081 & 1.060 & 1.040 & 1.020 \\
\hline & 770 & 1.088 & 1.067 & 1.047 & 1.027 \\
\hline & 775 & 1.095 & 1.074 & 1.054 & 1.034 \\
\hline & 780 & 1.102 & 1.081 & 1.061 & 1.041 \\
\hline
\end{tabular}

Table XII is a copy of the table of density of water by P. Chappuis (Vol. XIII, Travaux et Memoires, Bureau International des Poids et Mesures, 1907). This quantity is $d_{t}$, used in formula (I). 
TABLE XII.-Expansion of Water according to P. Chappuis.

Density of pure water free from air, by tenths of degrees from $0^{\circ}$ to $40^{\circ}$ and under standard pressure.

\begin{tabular}{|c|c|c|c|c|c|c|c|c|c|c|c|c|}
\hline \multirow{2}{*}{ 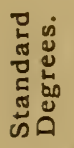 } & \multicolumn{11}{|c|}{ Tenths of Degrees. } & \multirow{2}{*}{$\begin{array}{l}\text { Mean } \\
\text { Differ- } \\
\text { ences. }\end{array}$} \\
\hline & o & & I & 2 & 3 & 4 & 5 & 6 & 7 & 8 & 9 & \\
\hline 0 & 0.999 & 8681 & 8747 & 8812 & 8875 & 8936 & 8996 & 9053 & 9109 & 9163 & 9216 & + \\
\hline 1 & & 9267 & 9315 & 9363 & $94 \mathrm{C} 8$ & 9452 & 9494 & 9534 & 9573 & 9610 & 9645 & + \\
\hline 2 & & 9679 & 9711 & 9741 & 9769 & 9796 & 9821 & 9844 & 9866 & 9887 & 9905 & + \\
\hline 3 & & 9922 & 9937 & 9951 & 9962 & 9973 & 9981 & 9988 & 9994 & 9998 & $* 0000$ & + \\
\hline 4 & 1.000 & 0000 & *9999 & *9996 & *9992 & *9986 & $* 9979$ & $* 9970$ & $* 9960$ & *9947 & *9934 & - \\
\hline 5 & 0.999 & 9919 & 9902 & 9884 & 9864 & 9842 & 9819 & 9795 & 9769 & 9742 & 9713 & - \\
\hline 6 & & 9682 & 9650 & 9617 & 9582 & 9545 & 9507 & 9468 & 9427 & 9385 & 9341 & - \\
\hline 7 & & 9296 & 9249 & 9201 & 9151 & 100 & 9048 & 8994 & 8938 & 8881 & 8823 & - \\
\hline 8 & & 8764 & 8703 & 8641 & 8577 & 8512 & 8445 & 8377 & 8308 & 8237 & 8165 & - \\
\hline 9 & & 8091 & 8017 & 7940 & 7863 & 7784 & 7704 & 7522 & 7539 & 7455 & 7369 & - \\
\hline 10 & & 7282 & 7194 & 7105 & 7014 & 6921 & 6826 & 6729 & 6632 & 6533 & 6432 & - \\
\hline 11 & & 6331 & 6228 & 6124 & 6020 & 5913 & 5805 & 5696 & 5586 & 5474 & 5362 & $-\quad 108$ \\
\hline 12 & & 5248 & 5132 & 5016 & 4898 & 4780 & 4660 & 4538 & 4415 & 4291 & 4166 & $-\quad 121$ \\
\hline 13 & & 4040 & 3912 & 3784 & 3654 & 3523 & 3391 & 3257 & 3122 & 2986 & 2850 & -133 \\
\hline 14 & & 2712 & 2572 & 2431 & 2289 & 2147 & 2003 & 1858 & 1711 & 1564 & 1416 & -145 \\
\hline 15 & & 1266 & 1114 & 0962 & 0809 & 0655 & 0499 & 0343 & 0185 & 0026 & *9865 & $-\quad 156$ \\
\hline 16 & 0.998 & 9705 & 9542 & 9378 & 9214 & 9048 & 8881 & 8713 & 8544 & 8373 & 8202 & -168 \\
\hline 17 & & 8029 & 7856 & 7681 & 7505 & 7328 & 7150 & 6971 & 6791 & 6610 & 6427 & -178 \\
\hline 18 & & 6244 & 6058 & 5873 & 5686 & 5498 & 5309 & 5119 & 4927 & 4735 & 4541 & -190 \\
\hline 19 & & 4347 & 4152 & 3955 & 3757 & 3558 & 3358 & 3158 & 2955 & 2752 & 2549 & -200 \\
\hline 20 & & 2343 & 2137 & 1930 & 1722 & 1511 & 1301 & 1090 & 0878 & 0663 & 0449 & $-\quad 211$ \\
\hline 21 & & 0233 & 0016 & *9799 & *9580 & *9359 & *9139 & $* 8917$ & $* 8694$ & $* 8470$ & $* 8245$ & $-\quad 221$ \\
\hline 22 & 0.997 & 8019 & 7792 & 7564 & 7335 & 7104 & 6873 & 6641 & 6408 & 6173 & 5938 & $-\quad 232$ \\
\hline 23 & & 5702 & 5466 & 5227 & 4988 & 4747 & 4506 & 4264 & 4021 & 3777 & 3531 & $-\quad 242$ \\
\hline 24 & & 3286 & 3039 & 2790 & 2541 & 2291 & 2040 & 1788 & 1535 & 1280 & 1026 & $-\quad 252$ \\
\hline 25 & & 0770 & 0513 & 0255 & *9997 & *9736 & $* 9476$ & *9214 & $* 8951$ & *8688 & $* 8423$ & $-\quad 261$ \\
\hline 26 & 0.996 & 8158 & 7892 & 7624 & 7356 & 7087 & 6817 & 6545 & 6273 & 6000 & 5726 & $-\quad 271$ \\
\hline 27 & & 5451 & 5176 & 4898 & 4620 & 4342 & 4052 & 3782 & 3500 & 3218 & 2935 & -280 \\
\hline 28 & & 2652 & 2366 & 2080 & 1793 & 1505 & 1217 & 0928 & 0637 & 0346 & 0053 & $-\quad 289$ \\
\hline 29 & 0.995 & 9761 & 9466 & 9171 & 8876 & 8579 & 8282 & 7983 & 7684 & 7383 & 7083 & $-\quad 298$ \\
\hline 30 & & 6780 & 6478 & 6174 & 5869 & 5564 & 5258 & 4950 & 4642 & 4334 & 4024 & $-\quad 307$ \\
\hline 31 & & 3714 & 3401 & 3089 & 2776 & 2462 & 2147 & 1832 & 1515 & 1198 & 0880 & $-\quad 315$ \\
\hline 32 & & 0561 & 0241 & *9920 & *9599 & *9276 & *8954 & $* 8630$ & *8304 & *7979 & $* 7653$ & $-\quad 324$ \\
\hline 33 & 0.994 & 7325 & 6997 & 6668 & 6338 & 6007 & 5676 & 5345 & 5011 & 4678 & 4343 & - 332 \\
\hline 34 & & 4007 & 3671 & 3335 & 2997 & 2659 & 2318 & 1978 & 1638 & 1296 & 0953 & -340 \\
\hline 35 & & 0610 & 0267 & *9922 & *9576 & *9230 & *8883 & $* 8534$ & *8186 & *7837 & *7486 & $-\quad 347$ \\
\hline 36 & 0.993 & 7136 & 6784 & 6432 & 6078 & 5725 & 5369 & 5014 & 4658 & 4301 & 3943 & $-\quad 355$ \\
\hline 37 & & 3585 & 3226 & 2866 & 2505 & 2144 & 1782 & 1419 & 1055 & 0691 & 0326 & -362 \\
\hline 38 & 0.992 & 9960 & 9593 & 9227 & 8859 & 8490 & 8120 & 7751 & 7380 & 7008 & 6636 & $-\quad 370$ \\
\hline 39 & & 6263 & 5890 & 5516 & 5140 & 4765 & 4389 & 4011 & 3634 & 3255 & 2876 & $-\quad 377$ \\
\hline 40 & & 2497 & 2116 & 1734 & 1352 & 0971 & 0587 & 0203 & *9818 & *9433 & $* 9047$ & $-\quad 384$ \\
\hline 41 & 0.991 & 8661 & & & & & & & & & & \\
\hline
\end{tabular}


Tables XIII to XVIII give the mass of certain volumes of water for temperatures between $5^{\circ}$ and $30^{\circ}$. This quantity is $M$ used in formula (2). These tables are calculated using the densities of water given in 'Table XII.

Table XIX gives for temperatures between $15^{\circ} \mathrm{C}$ and $30^{\circ} \mathrm{C}$, the apparent weight in air, humidity $5^{\circ}$ per cent, unreduced barometer reading $760 \mathrm{~mm}$, of certain volumes of water weighed with brass weiglits. This quantity is A, used in formula (3). This table is based on the data given in Table XI and Tables XIII to XVIII, and may be conveniently enployed to obtain desired volumes of water for calibrating instruments. The table assumes the air to be at the sane temperature as the water.

Table XX gives the correction to be added to capacities of glass instruments determined at various temperatures to give the capacity at $20^{\circ} \mathrm{C}$. By subtracting the corrections from the indicated capacity of an instrument standard at $20^{\circ} \mathrm{C}$ the capacity at other temperatures is obtained. This quantity is $v a(20-t)$ in formula (4). The table assumes for the cubical coefficient of expansion of glass 0.000025 per degree centigrade.

Table XXI gives the density of dry air containing .04 per cent of $\mathrm{CO}_{2}$ at various temperatures and pressures. This table is computed from the formula:

$$
\rho=\frac{\mathrm{I} .293052}{\mathrm{I}+0.00367} \times \frac{h}{760}
$$

where $h$ is pressure in $m m$ of mercury at $o^{\circ} \mathrm{C}$, and standard gravity. This table miay be used in precise work, for reducing to vacua weighings made in air. 
TABLE XIII.-Mass of $2000 \mathrm{cc}$ of Water.

\begin{tabular}{|c|c|c|c|c|c|c|c|c|c|c|}
\hline \multirow{2}{*}{ 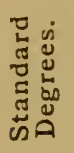 } & \multicolumn{10}{|c|}{ Tenths of Degrees. } \\
\hline & $\circ$ & I & 2 & 3 & 4 & 5 & 6 & 7 & 8 & 9 \\
\hline 15 & 1998.253 & 223 & 192 & 162 & 131 & 100 & 069 & 037 & 005 & $* 973$ \\
\hline 16 & 1997.941 & 908 & 876 & 843 & 810 & 776 & 743 & 709 & 675 & 640 \\
\hline 17 & 1997.606 & 571 & 536 & 501 & 466 & 430 & 394 & 358 & 322 & 285 \\
\hline 18 & 1997.249 & 212 & 175 & 137 & 100 & 062 & 024 & *985 & $\ddot{*} 947$ & *908 \\
\hline 19 & 1996.869 & 830 & 791 & 751 & 712 & 672 & 632 & 591 & 550 & 510 \\
\hline 20 & 1996.469 & 427 & 386 & 344 & 302 & 260 & 218 & 176 & 133 & 090 \\
\hline 21 & 1996.047 & 003 & $* 960$ & \%916 & $* 872$ & *828 & *783 & 并739 & *694 & *649 \\
\hline 22 & 1995.604 & 558 & 513 & 467 & 421 & 375 & 328 & 282 & 235 & 188 \\
\hline 23 & 1995.140 & 093 & 045 & *998 & $\because 949$ & $\because 901$ & *853 & $* 804$ & $* 755$ & $* 706$ \\
\hline 24 & 1994.657 & 608 & 558 & 508 & 458 & 408 & 358 & 307 & 256 & 205 \\
\hline 25 & 1994.154 & 103 & 051 & \%999 & $* 947$ & $\div 895$ & *843 & *790 & $* 738$ & *685 \\
\hline 26 & 1993.632 & 578 & 525 & 471 & 417 & 363 & 309 & 255 & 200 & 145 \\
\hline 27 & 1993.090 & 035 & $* 980$ & *924 & $* 868$ & $\because 812$ & $* 756$ & $* 700$ & $* 644$ & $\because 587$ \\
\hline 28 & 1992.530 & 473 & 416 & 359 & 301 & 243 & 186 & 127 & 069 & 011 \\
\hline 29 & 1991.952 & 893 & 834 & 775 & 716 & 656 & 597 & 537 & 477 & 417 \\
\hline
\end{tabular}

TABLE XIV.-Mass of 1000 cc of Water.

\begin{tabular}{|c|c|c|c|c|c|c|c|c|c|c|}
\hline \multirow{2}{*}{ 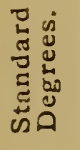 } & \multicolumn{10}{|c|}{ Tenths of Degrees. } \\
\hline & 0 & I & 2 & 3 & 4 & 5 & 6 & 7 & 8 & 9 \\
\hline 15 & 999.127 & 111 & *096 & *081 & *066 & ${ }^{*} 050$ & *034 & *018 & *003 & *986 \\
\hline 16 & 998.970 & 954 & 938 & 921 & 905 & 888 & 871 & 854 & 837 & 820 \\
\hline 17 & 998.803 & 786 & 768 & 750 & 733 & 715 & 697 & 679 & 661 & 643 \\
\hline 18 & 998.624 & 606 & 587 & 569 & 550 & 531 & 512 & 493 & 474 & 454 \\
\hline 19 & 998.435 & 415 & 396 & 376 & 356 & 336 & 316 & 296 & 275 & 255 \\
\hline 20 & 998.234 & 214 & 193 & 172 & 151 & 130 & 109 & 088 & 066 & 045 \\
\hline 21 & 998.023 & 002 & $* 980$ & *958 & *936 & *914 & $\because 892$ & $* 869$ & $* 847$ & ${ }^{*} 824$ \\
\hline 22 & 997.802 & 779 & 756 & 734 & 710 & 687 & 664 & 641 & 617 & 594 \\
\hline 23 & 997.570 & 547 & 523 & 499 & 475 & 451 & 426 & 402 & 378 & 353 \\
\hline 24 & 997.329 & 304 & 279 & 254 & 229 & 204 & 179 & 154 & 128 & 103 \\
\hline 25 & 997.077 & 051 & 026 & 000 & *974 & *948 & *921 & *895 & $\because 869$ & *842 \\
\hline 26 & 996.816 & 789 & 762 & 736 & 709 & 682 & 654 & 627 & 600 & 573 \\
\hline 27 & 996.545 & 518 & 490 & 462 & 434 & 406 & 378 & 350 & 322 & 294 \\
\hline 28 & 996.265 & 237 & 208 & 179 & 150 & 122 & 093 & 064 & 035 & 005 \\
\hline 29 & 995.976 & 947 & 917 & 888 & 858 & 828 & 798 & 768 & 738 & 708 \\
\hline
\end{tabular}


Bulletin of the Bureau of Standards. [Vol.4, No.4.

TABLE XV.-Mass of $500 \mathrm{cc}$ of Water.

\begin{tabular}{|c|c|c|c|c|c|c|c|c|c|c|}
\hline \multirow{2}{*}{ 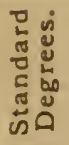 } & \multicolumn{10}{|c|}{ Tenths of Degrees. } \\
\hline & $\circ$ & I & 2 & 3 & 4 & 5 & 6 & 7 & 8 & 9 \\
\hline 15 & 499.563 & 556 & 548 & 540 & 533 & 525 & 517 & 509 & 501 & 493 \\
\hline 16 & 499.485 & 477 & 469 & 461 & 452 & 444 & 436 & 427 & 419 & 410 \\
\hline 17 & 499.401 & 393 & 384 & 375 & 366 & 358 & 349 & 340 & 330 & 321 \\
\hline 18 & 499.312 & 303 & 294 & 284 & 275 & 265 & 256 & 246 & 237 & 227 \\
\hline 19 & 499.217 & 208 & 198 & 188 & 178 & 168 & 158 & 148 & 138 & 127 \\
\hline 20 & 499.117 & 107 & 096 & 086 & 076 & 065 & 054 & 044 & 033 & 022 \\
\hline 21 & 499.012 & 001 & $\because \ddot{9900}$ & $* 979$ & *968 & $* 957$ & *946 & $\because 935$ & *924 & *912 \\
\hline 22 & 498.901 & 890 & 878 & 867 & 855 & 844 & 832 & 820 & 809 & 797 \\
\hline 23 & 498.785 & 773 & 761 & 749 & 737 & 725 & 713 & 701 & 689 & 677 \\
\hline 24 & 498.664 & 652 & 640 & 627 & 615 & 602 & 589 & 577 & 564 & 551 \\
\hline 25 & 498.538 & 526 & 513 & 500 & 487 & 474 & 461 & 448 & 434 & 421 \\
\hline 26 & 498.408 & 395 & 381 & 368 & 354 & 341 & 327 & 314 & 300 & 286 \\
\hline 27 & 498.273 & 259 & 245 & 231 & 217 & 203 & 189 & 175 & 161 & 147 \\
\hline 28 & 498.133 & 118 & 104 & 090 & 075 & 061 & 046 & 032 & 017 & 003 \\
\hline 29 & 497.988 & 973 & 959 & 944 & 929 & 914 & 899 & 884 & 869 & 854 \\
\hline
\end{tabular}

TABLE XVI.-Mass of $400 \mathrm{cc}$ of Water.

\begin{tabular}{|c|c|c|c|c|c|c|c|c|c|c|}
\hline \multirow{2}{*}{ 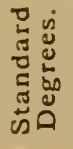 } & \multicolumn{10}{|c|}{ Tenths of Degrees. } \\
\hline & o & I & 2 & 3 & 4 & 5 & 6 & 7 & 8 & 9 \\
\hline 15 & 399.651 & 645 & 638 & 632 & 626 & 620 & 614 & 607 & 601 & 595 \\
\hline 16 & 399.588 & 582 & 575 & 569 & 562 & 555 & 549 & 542 & 535 & 528 \\
\hline 17 & 399.521 & 514 & 507 & 500 & 493 & 486 & 479 & 472 & 464 & 457 \\
\hline 18 & 399.450 & 442 & 435 & 427 & 420 & 412 & 405 & 397 & 389 & 382 \\
\hline 19 & 399.374 & 366 & 358 & 350 & 342 & 334 & 326 & 318 & 310 & 302 \\
\hline 20 & 399.294 & 285 & 277 & 269 & 260 & 252 & 244 & 235 & 227 & 218 \\
\hline 21 & 339.209 & 201 & 192 & 183 & 174 & 166 & 157 & 148 & 139 & 130 \\
\hline 22 & 399.121 & 112 & 103 & 093 & 084 & 075 & 066 & 056 & 047 & 038 \\
\hline 23 & 399.028 & 019 & 009 & 000 & *990 & \%980 & $* 971$ & *961 & $\stackrel{\circ 951}{*}$ & $\div 941$ \\
\hline 24 & 398.931 & 922 & 912 & 902 & 892 & 882 & 872 & 861 & 851 & 841 \\
\hline 25 & 398.831 & 821 & 810 & 800 & 789 & 779 & 769 & 758 & 748 & 737 \\
\hline 26 & 398.726 & 716 & 705 & 694 & 683 & 673 & 662 & 651 & $64 \theta$ & 629 \\
\hline 27 & 398.618 & 607 & 596 & 585 & 574 & 562 & 551 & 540 & 529 & 517 \\
\hline 28 & 398.506 & 495 & 483 & 472 & 460 & 449 & 437 & 425 & 414 & 402 \\
\hline 29 & 398.390 & 379 & 367 & 355 & 343 & 331 & 319 & 307 & 295 & 283 \\
\hline
\end{tabular}


TABLE XVII.-Mass of $300 \mathrm{cc}$ of Water.

\begin{tabular}{|c|c|c|c|c|c|c|c|c|c|c|}
\hline \multirow{2}{*}{ 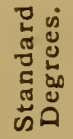 } & \multicolumn{10}{|c|}{ Tenths of Degrees. } \\
\hline & o & I & 2 & 3 & 4 & 5 & 6 & 7 & 8 & 9 \\
\hline 15 & 299.738 & 733 & 729 & 724 & 720 & 715 & 710 & 705 & 701 & 696 \\
\hline 16 & 299.691 & 686 & 681 & 676 & 671 & 666 & 661 & 656 & 651 & 646 \\
\hline 17 & 299.641 & 636 & 630 & 625 & 620 & 614 & 609 & 603 & 598 & 593 \\
\hline 18 & 299.587 & 582 & 576 & 570 & 565 & 559 & 554 & 548 & 542 & 536 \\
\hline 19 & 299.530 & 524 & 519 & 513 & 507 & 501 & 495 & 489 & 483 & 476 \\
\hline 20 & 299.470 & 464 & 458 & 452 & 445 & 439 & 433 & 426 & 420 & 413 \\
\hline 21 & 399.407 & 400 & 394 & 387 & 381 & 374 & 367 & 361 & 354 & 347 \\
\hline 22 & 299.341 & 334 & 327 & 320 & 313 & 306 & 299 & 292 & 285 & 278 \\
\hline 23 & 299.271 & 264 & 257 & 250 & 242 & 235 & 228 & 221 & 213 & 206 \\
\hline 24 & 299.199 & 191 & 184 & 176 & 169 & 161 & 154 & 146 & 138 & 131 \\
\hline 25 & 299.123 & 115 & 108 & 100 & 092 & 084 & 076 & 069 & 061 & 053 \\
\hline 26 & 299.045 & 037 & 029 & 021 & 013 & 005 & *996 & *988 & *980 & *972 \\
\hline 27 & 298.964 & 955 & 947 & 939 & 930 & 922 & 913 & 905 & 897 & 888 \\
\hline 28 & 298.880 & 871 & 862 & 854 & 845 & 837 & 828 & 819 & 810 & 802 \\
\hline 29 & 298.793 & 784 & 775 & 766 & 757 & 748 & 739 & 731 & 721 & 712 \\
\hline
\end{tabular}

TABLE XVIII.-Mass of $250 \mathrm{cc}$ of Water.

\begin{tabular}{|c|c|c|c|c|c|c|c|c|c|c|}
\hline \multirow{2}{*}{ 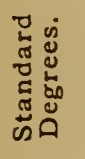 } & \multicolumn{10}{|c|}{ Tenths of Degrees. } \\
\hline & $\circ$ & I & 2 & 3 & 4 & 5 & 6 & 7 & 8 & 9 \\
\hline 15 & 249.782 & 778 & 774 & 770 & 766 & 762 & 759 & 755 & 751 & 747 \\
\hline 16 & 249.743 & 739 & 734 & 730 & 726 & 722 & 718 & 714 & 709 & 705 \\
\hline 17 & 249.701 & 696 & 692 & 688 & 683 & 679 & 674 & 670 & 665 & 661 \\
\hline 18 & 249.656 & 651 & 647 & 642 & 637 & 633 & 628 & 623 & 618 & 614 \\
\hline 19 & 249.609 & 604 & 599 & 594 & 589 & 584 & 579 & 574 & 569 & 564 \\
\hline 20 & 249.559 & 553 & 548 & 543 & 538 & 533 & 527 & 522 & 517 & 511 \\
\hline 21 & 249.506 & 500 & 495 & 490 & 484 & 478 & 473 & 467 & 462 & 456 \\
\hline 22 & 249.450 & 445 & 439 & 433 & 428 & 422 & 416 & 410 & 404 & 398 \\
\hline 23 & 249.393 & 387 & 381 & 375 & 369 & 363 & 357 & 351 & 344 & 338 \\
\hline 24 & 249.332 & 326 & 320 & 314 & 307 & 301 & 295 & 288 & 282 & 276 \\
\hline 25 & 249.269 & 263 & 256 & 250 & 243 & 237 & 230 & 224 & 217 & 211 \\
\hline 26 & 249.204 & 197 & 191 & 184 & 177 & 170 & 164 & 157 & 150 & 143 \\
\hline 27 & 249.136 & 129 & 122 & 116 & 109 & 102 & 095 & 088 & 080 & 073 \\
\hline 28 & 249.066 & 059 & 052 & 045 & 038 & 030 & 023 & 016 & 009 & 001 \\
\hline 29 & 248.994 & 987 & 979 & 972 & 964 & 957 & 950 & 942 & 935 & 927 \\
\hline
\end{tabular}


TABLE XIX.-Apparent Weight in Air of Water.

\begin{tabular}{|c|c|c|c|c|c|c|c|}
\hline 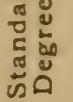 & $2000 \mathrm{cc}$ & $1000 \mathrm{cc}$ & $500 \mathrm{cc}$ & $400 \mathrm{cc}$ & $300 \mathrm{cc}$ & $250 \mathrm{cc}$ & $150 \mathrm{cc}$ \\
\hline 15 & 1996.11 & 998.05 & 499.03 & 399.22 & 299.42 & 249.51 & 149.71 \\
\hline 16 & 1995.80 & 997.90 & 498.95 & 399.16 & 299.37 & 249.48 & 149.68 \\
\hline 17 & 1995.48 & 997.74 & 498.87 & 399.10 & 299.32 & 249.43 & 149.66 \\
\hline 18 & 1995.13 & 997.56 & 498.78 & 399.03 & 299.27 & 249.39 & 149.63 \\
\hline 19 & 1994.76 & 997.38 & 498.69 & 398.95 & 299.21 & 249.34 & 149.61 \\
\hline 20 & 1994.36 & 997.18 & 498.59 & 398.87 & 299.15 & 249.30 & 149.58 \\
\hline 21 & 1993.95 & 996.97 & 498.49 & 398.79 & 299.09 & 249.24 & 149.55 \\
\hline 22 & 1993.51 & 996.76 & 498.38 & 398.70 & 299.03 & 249.19 & 149.51 \\
\hline 23 & 1993.06 & 996.53 & 498.26 & 398.61 & 298.96 & 249.13 & 149.48 \\
\hline 24 & 1992.58 & 996.29 & 498.15 & 398.52 & 298.89 & 249.07 & 149.44 \\
\hline 25 & 1992.09 & 996.04 & 498.02 & 398.42 & 298.81 & 249.01 & 149.41 \\
\hline 26 & 1991.57 & 995.79 & 497.89 & 398.31 & 298.74 & 248.95 & 149.37 \\
\hline 27 & 1991.04 & 995.52 & 497.76 & 398.21 & 298.66 & 248.88 & 149.33 \\
\hline 28 & 1990.49 & 995.24 & 497.62 & 398.10 & 298.57 & 248.81 & 149.29 \\
\hline 29 & 1989.92 & 994.96 & 497.48 & 397.98 & 298.49 & 248.74 & 149.24 \\
\hline 30 & 1989.33 & 994.66 & 497.33 & 397.87 & 298.40 & 248.67 & 149.20 \\
\hline
\end{tabular}

TABLE XX.-Temperature Correction.

\begin{tabular}{|c|c|c|c|c|c|c|}
\hline 。 & $2000 \mathrm{cc}$ & $1000 \mathrm{cc}$ & $500 \mathrm{cc}$ & $400 \mathrm{cc}$ & $300 \mathrm{cc}$ & $250 \mathrm{cc}$ \\
\hline 15 & +0.25 & +0.12 & +0.06 & +0.05 & +0.04 & +0.031 \\
\hline 16 & +.20 & +.10 & +.05 & +.04 & +.03 & +.025 \\
\hline 17 & +.15 & +.08 & +.04 & +.03 & +.02 & +.019 \\
\hline 18 & +.10 & +.05 & +.02 & +.02 & +.02 & +.012 \\
\hline 19 & +.05 & +.02 & +.01 & +01 & +.01 & +.006 \\
\hline 21 & -0.05 & -0.02 & -0.01 & -0.01 & -0.01 & -0.006 \\
\hline 22 & -.10 & -.05 & -.02 & -.02 & -.02 & -.012 \\
\hline 23 & -.15 & -.08 & -.04 & -.03 & -.02 & -.019 \\
\hline 24 & -.20 & --.10 & -.05 & -.04 & -.03 & -.025 \\
\hline 25 & --.25 & -.12 & -.06 & -.05 & -.04 & -.031 \\
\hline 26 & -0.30 & -0.15 & -0.08 & -0.06 & -0.04 & -0.038 \\
\hline 27 & -.35 & -.18 & -.09 & -.07 & -.05 & -.044 \\
\hline 28 & -.40 & -.20 & -.10 & -.08 & -.06 & -.050 \\
\hline 29 & -.45 & -.22 & -.11 & -.09 & -.07 & -.056 \\
\hline 30 & -.50 & -.25 & -.12 & -.10 & -.08 & -.062 \\
\hline
\end{tabular}




\begin{tabular}{|c|c|c|c|}
\hline & & אִ & 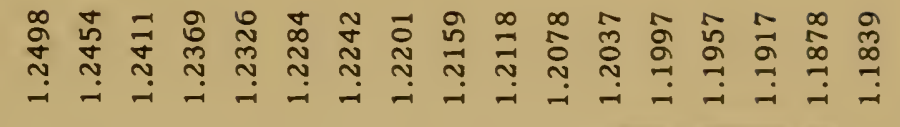 \\
\hline & & $\stackrel{8}{\wedge}$ & 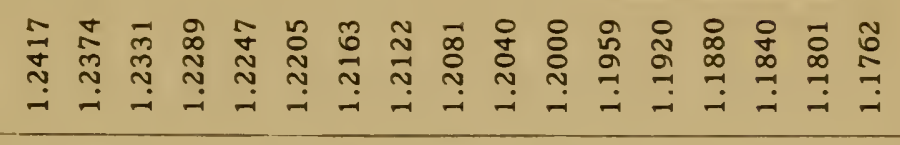 \\
\hline Uू & & $\stackrel{\leftrightarrow}{n}$ & 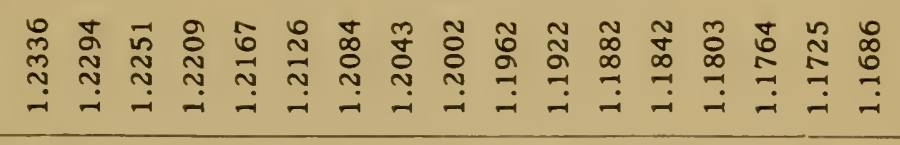 \\
\hline $\begin{array}{l}20 \\
0 \\
0\end{array}$ & $\stackrel{\lambda}{=}$ & 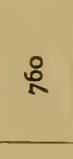 & 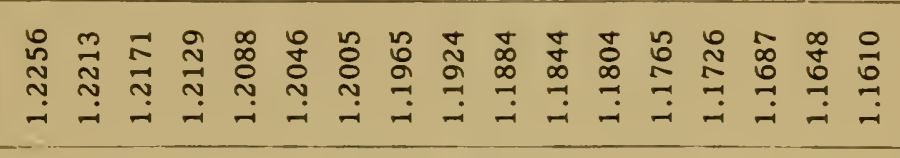 \\
\hline 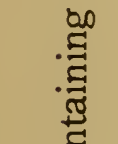 & 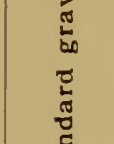 & 员 & 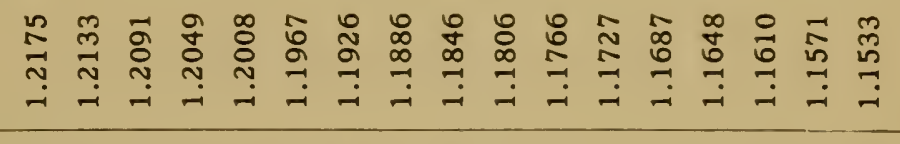 \\
\hline ن & $\begin{array}{l}\frac{\pi}{5} \\
\vdots \\
\vdots \\
0 \\
0\end{array}$ & 员 & 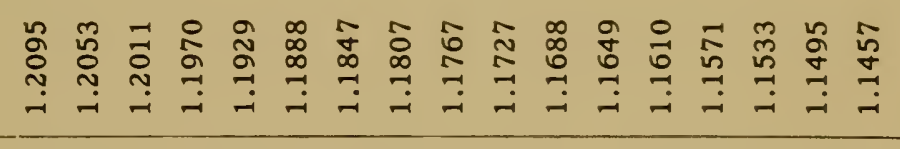 \\
\hline $\begin{array}{l}\vec{H} \\
\text { 嵅 }\end{array}$ & 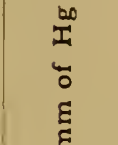 & 疍 & 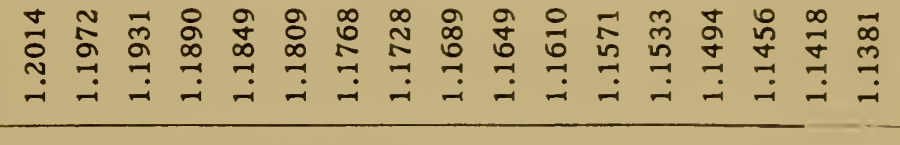 \\
\hline 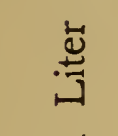 & 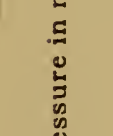 & $\stackrel{\&}{2}$ & 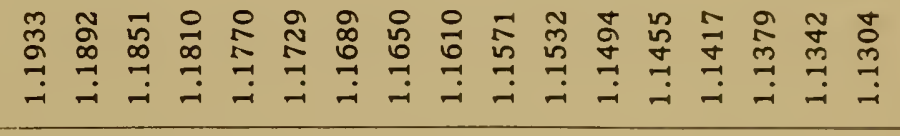 \\
\hline 㟧 & ڤे & $\stackrel{\check{n}}{n}$ & 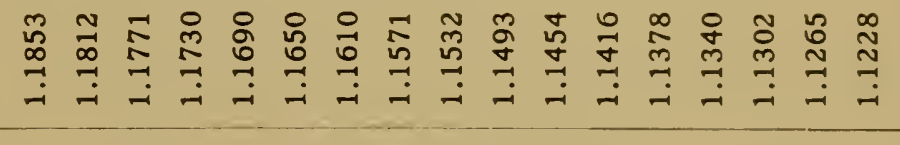 \\
\hline $\begin{array}{l}\stackrel{\pi}{0} \\
. \Xi\end{array}$ & & $\stackrel{\circ}{\circ}$ & 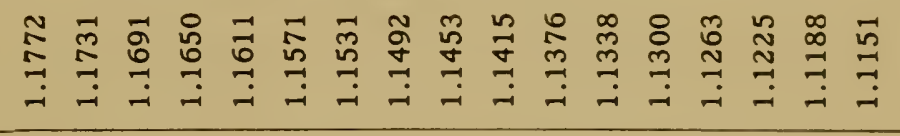 \\
\hline 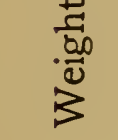 & & $\stackrel{\infty}{\infty}$ & 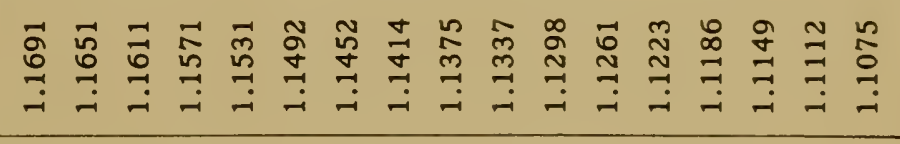 \\
\hline & & $\stackrel{8}{\circ}$ & 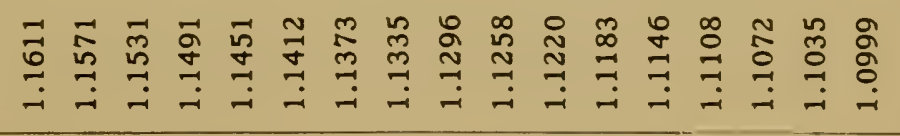 \\
\hline & & & $\overrightarrow{-1}$ \\
\hline
\end{tabular}

Washington, April io, igo8. 